\title{
Antioxidants Maintain Cellular Redox Homeostasis by Elimination of Reactive Oxygen Species
}

\author{
Long $\mathrm{He}^{\mathrm{a}}$ Ting He $\mathrm{He}^{\mathrm{a}}$ Shabnam Farrar ${ }^{\mathrm{b}}$ Linbao Jia Tianyi Liu ${ }^{\mathrm{a}} \quad \mathrm{Xi} \mathrm{Ma}^{\mathrm{a}, \mathrm{c}}$ \\ aState Key Laboratory of Animal Nutrition, China Agricultural University, Beijing, China, bCollege of \\ Dental Medicine, Midwestern University, Downers Grove, USA, 'Department of Internal Medicine, \\ Department of Biochemistry, University of Texas Southwestern Medical Center, Dallas, USA
}

\section{Key Words}

Antioxidants • Reactive oxygen species • Cytochrome P450 enzymes • Autophagy • Apoptosis - Necrosis

\begin{abstract}
Reactive oxygen species (ROS) are produced by living cells as normal cellular metabolic byproduct. Under excessive stress conditions, cells will produce numerous ROS, and the living organisms eventually evolve series of response mechanisms to adapt to the ROS exposure as well as utilize it as the signaling molecules. ROS molecules would trigger oxidative stress in a feedback mechanism involving many biological processes, such as apoptosis, necrosis and autophagy. Growing evidences have suggested that ROS play a critical role as the signaling molecules throughout the entire cell death pathway. Overwhelming production of ROS can destroy organelles structure and bio-molecules, which lead to inflammatory response that is a known underpinning mechanism for the development of diabetes and cancer. Cytochrome P450 enzymes (CYP) are regarded as the markers of oxidative stress, can transform toxic metabolites into ROS, such as superoxide anion, hydrogen peroxide and hydroxyl radical which might cause injury of cells. Accordingly, cells have evolved a balanced system to neutralize the extra ROS, namely antioxidant systems that consist of enzymatic antioxidants such as superoxide dismutase (SOD), catalase (CAT) and glutathione peroxidases (GPxs), thioredoxin (Trx) as well as the non-enzymatic antioxidants which collectively reduce oxidative state. Herein, we review the recent novel findings of cellular processes induced by ROS, and summarize the roles of cellular endogenous antioxidant systems as well as natural anti-oxidative compounds in several human diseases caused by ROS in order to illustrate the vital role of antioxidants in prevention against oxidative stress.

\section{Introduction}

Generally, endogenous and physiological reactive oxygen species (ROS) are mainly generated in the oxidative reaction process of mitochondrial respiratory chain as byproducts 
of normal cellular metabolism [1]. ROS have comprehensive influence in cell physiology. Moderate amounts of ROS have positive effects including killing of invading pathogens, wound healing and repairing processes [2]. Briefly, the source of cytosol ROS include mitochondria and cytochrome P450 enzymes (CYP) system. Mitochondrial ROS is the very important potential ROS pool and sealed in the double membranes of mitochondria. The high oxygen and metabolic level will elevate the ROS production, and increasing mitochondrial membrane permeability will directly lead to the release of ROS to the cytosol. However, in certain conditions, such as the invasion of xenobiotic substance, the xenobiotic metabolic process in responses to the exposure to toxic compounds by the CYP can be another crucial important source of ROS. Excessive ROS exposure will disrupt the redox homeostasis, lead to the oxidative stress and ROS-mediated damage of the important organelles and biomolecules such as DNA and proteins as well as the injuries implicated in carcinogenesis [3], diabetes [4, 5], neurodegeneration [6, 7] and aging [8,9]. Oxidative stress is considered to be an important factor to promote cell death in response to a variety of signals and pathophysiological situations. For instance, apoptotic response induced by the transforming growth factor $\beta$ in fetal hepatocytes is mediated by ROS [10]. ROS are also the necrosis inducer [11] and activator of autophagy [12], which are the switches of cell survival and death. Cells harbor the comprehensive defense system against excessive ROS exposure. In addition to ROS, reactive nitrogen species (RNS) such as nitric oxide (NO), nitrogen dioxide $\left(\mathrm{NO}_{2}^{-}\right)$, peroxynitrite (OONO-), dinitrogen trioxide $\left(\mathrm{N}_{2} \mathrm{O}_{3}\right)$, and nitrous acid $\left(\mathrm{HNO}_{2}\right)$ also contribute to the oxidative stress [13]. NO is produced by three different isoforms of nitric oxide synthases (NOs), which catalyze L-arginine to L-citrulline by releasing the NO. Interestingly, NO as a small molecule has been proved to function in activation of AMP-activated protein kinase (AMPK) which is the powerful kinase in regulate energy and metabolic homeostasis [14]. Cellular NO interacts with ROS to cause the production of several RNS that are implicated in oxidative and nitrosative damage. Drugs as well as endogenous antioxidants such as superoxide dismutase (SOD), peroxidase, glutathione (GSH) and vitamin E have been discovered to eliminate the ROS. Due to CYP monoxygenases are a major source of ROS during ischemia/reperfusion [15]. Therapeutics that can inhibit the CYP activity has the potentials in protecting cells against from ROS-induced damage $[16,17]$. Inhibition of ROS-induced cell injury by natural antioxidant or the synthetic compounds should be investigated for the better understanding their potentials in the treatment of diseases which originated from the excessive ROS exposure.

\section{Generation of ROS and Oxidative Stress}

In aerobic organisms, oxygen is essential for efficientenergy production, but paradoxically, overwhelming of cellular energy metabolism and oxygen consumption are coupled with the generation of ROS which produce chronic toxic stress in cells. Thus, a reduction in metabolic rate reduces the formation of ROS, which may produce beneficial effect [18]. The metabolism of toxic compounds such as alcohol might accelerate the production of the toxic byproducts including ROS. ROS will attack the liver cells with its active metabolites, and the excessive production of ROS in liver is the main etiological factor for alcohol poisoning with severe depletion of endogenous antioxidants such as GSH. Therefore, replenishing the reducing power is the main antidote for alcohol poisoning treatment [19].

The metabolism of toxic compounds in the cellular enzymatic system is not totally efficient and sometimes the metabolic processes lead to the production of the byproducts including ROS which are more toxic than their parental compounds. For example, the metabolism of the toxic environmental contaminant benzo-a-pyrene produced by the CYP will lead to its metabolic activation into highly reactive byproducts which are carcinogenic. Therefore, exogenous toxicants are potential sources of ROS produced by CYP metabolism. The CYP enzymes are a super-family of monooxygenases and many of which are responsible for the detoxification of xenobiotics. Notably, CYP families appear to be the major members

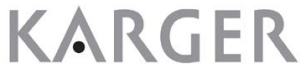


of the first pass metabolic enzymes in the phase I reaction for the metabolism of the xenobiotics such as drugs and carcinogens as well as endogenous substrates such as steroids and hormones. Upon encountering substrates, CYP binds to the target compound via the combination of one molecule of oxygen to form an oxy complex. The oxy complex reduced to peroxy complex that accepts two protons and produces water through intermediate reaction. CYP transform the drugs, the following ROS generation result in nicotinamide adenine dinucleotide phosphate (NADPH) consumption by the CYP molecules [20]. The electrontransfer chain of microsome continues to deplete NADPH and promote the production of ROS even without any substrates. These overwhelming amounts of ROS give feedback to CYP gene repression [21]. Besides, many enzymes such as lipooxygenase and xanthine oxidase can also contribute to the ROS production. These ROS particularly superoxide radical get protonated to form perhydroxyl radical that plays a significant role in lipid peroxidation and membrane destabilization [22].

CYP are a very large gene family containing 57 CYP genes which are classified into 18 families and 44 subfamilies. However, only the 1, 2, and 3 CYP families are involved in phase I drug metabolism. CYP1A1, CYP1A2, CYP2A6, CYP2B6, CYP2C8, CYP2C9, CYP2C19, CYP2D6, CYP2E1 and CYP3A4/5 are the CYP isoforms which function in the metabolism of therapeutic agents [23]. The production of ROS arises from the release of superoxide anion radical due to the decay of the one-electron-reduced ternary complex and the protonation of the CYP with the formation of hydrogen peroxide [24]. CYP2E1 has been demonstrated to be activated under diverse pathophysiological conditions including diabetes, obesity, starvation, cancer, alcohol liver disease, and non-alcoholic hepatic steatosis [25]. CYP2E1 as the powerful enzyme plays a role in oxidative stress in addition to carcinogenesis and chemical toxicity [26], as well as alcohol-mediated liver injury [27]. Moreover, the mitochondria-targeted CYP2E1 directly promotes the alcohol-mediated oxidative stress, mitochondrial DNA damage, and mitochondrial dysfunction in cells as well as the induction of oxidative stress in livers of ethanol-fed rats [28]. Besides the oxidative stress induced by CYP2E1, the induction of non-alcoholic steatohepatitis by CYP2E1 have been studied. As a member of the oxidoreductase cytochrome family, CYP2E1 is also involved in the oxidization of xenobiotics and fatty acids $[29,30]$. CYP2E1 expression was increased in some condition such as in obesity and fatty liver diseases, which is appear to be correlated with the severity of non-alcoholic fatty liver disease [31].

Many xenobiotic receptors are involved in the activation of CYP gene expression and these receptors include the aryl hydrocarbon receptor (AhR), pregnant X receptor (PXR) and constitutive androstane receptor (CAR) [32]. The expression of the CYP1 gene family (1A1, $1 \mathrm{~A} 2$ and $1 \mathrm{~B} 1)$ is transcriptionally regulated by AhR while the CYP2 $(2 \mathrm{~A} 6,2 \mathrm{~B} 6$ and 2C8/9) as well as CYP3 (3A4) families are regulated by the PXR and CAR [33]. AhR is a ligand-dependent transcription factor to mediate the biotransformation and carcinogenic/teratogenic effects of environmental toxins [33]. In most conditions, AhR is retained in the cytosol and formed complexes with the chaperone proteins, heat-shock protein $90 \mathrm{kDa}$ (HSP90), aryl hydrocarbon receptor interacting protein (AIP), and p23 in the absence of a ligand. Ligand binding to AhR results in transformation of the $\mathrm{AhR}$ and releases it from complex and translocate into the nucleus where it forms complex with the aryl hydrocarbon receptor nuclear translocator (ARNT). The AhR-ARNT complex interacts with the core DNA sequences located in the regulatory regions of CYP genes, notably the CYP1A1 and the heterodimer function as the transcription factor triggering a cascade of transcriptional activities and leading to the gene activation. The CYP2B1 is mainly regulated by CAR, however, it has also been found to be regulated by the PXR, and the CYP3As are mainly regulated by the PXR have been found to be regulated by the CAR $[34,35]$. Studies have indicated that there are cross-talk between the PXR and CAR-regulated gene expression and the cross-talk mainly mediated by the reciprocal bindings of the PXR-RXR and CAR-RXR complexes in the regulatory region of the genes [34].

In mitochondria, oxidative phosphorylation process as consuming $\mathrm{O}_{2}$ is the major source of ATP production. ATP production process couples with the ATP synthase activity through the electron transporting chain (ETC). However, during the electrons passing through

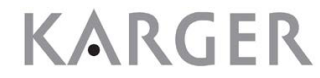


the ETC, electrons can escape and be captured by $\mathrm{O}_{2}$ to form the ROS. The ETC complexes comprise four different members: NADH: ubiquinone oxidoreductase (complex I), succinate dehydrogenase (complex II), ubiquinol: cytochrome c oxidoreductase (complex III) and cytochrome c oxidase (complex IV) [36]. The initiation process of electron transferring process from the tricarboxylic acid (TCA) cycle is delivering two electrons from NADH or succinate to complexes I and II, respectively, and the electrons are delivered to the CoEnzyme $\mathrm{Q}(\mathrm{CoQ})$ pool, a lipophilic electron carrier existing as oxidized ubiquinone and reduced ubiquinol. The electrons donated from complex I and II finally go into the CoQ pool and then passed through complex III to cytochrome c. At last, the electrons reduce oxygen to water by the complex IV. In the ETC process, protons are pumped into the intermembrane space by complexes I, III and IV to form a proton gradient across the mitochondrial inner membrane which is necessary for the catalysis of the ATP synthase. However, in addition to its proton gradient building function, the electrons escape from ETC continuously generates ROS [37]. When the electrons are donated to complex III, a free radical, ubisemiquinone, is transiently created. ETC sites that are implicated in ROS generation include complexes I, II, III and ubisemiquinone. Complex IV delivers electrons to $\mathrm{O}_{2}$ which could generate ROS. Complex V does not participate in electron transport, and there is no evidence that it directly generates ROS. Whereas, the alteration of complex $\mathrm{V}$ activity can makes changes in the membrane potential, then affects ROS generation from the ETC [38].

\section{ROS Signaling Transduction and Cellular Process}

ROS are reactive molecules, as the primary source of cellular oxidative stress molecules can oxidize DNA, proteins, and lipids. At physiological levels, ROS are also the important signaling molecules which transmit signals for normal physiological processes. However, excessive ROS promote the activation of autophagy, apoptosis and necrosis (Fig. 1).

\section{ROS Induce Autophagy}

Autophagy is a highly regulated cellular degradation system which degrades damaged organelles, protein aggregates and invading microorganisms through lysosomes. Dysfunction of autophagy has been implicated in a broad spectrum of human diseases including cancers, neurodegeneration, infectious diseases, metabolic diseases and aging [39]. Autophagy can be activated under stress conditions such as starvation, endoplasmic reticulum (ER) stress, and organelles damage and pathogen infection. ROS have become a very important factor to activate autophagy. Accumulation of $\mathrm{H}_{2} \mathrm{O}_{2}$ in the cell will become the source of oxidative stress. ATG4 is an essential autophagy gene involving in the autophagic pathway. This gene has been identified as a direct target for oxidation by $\mathrm{H}_{2} \mathrm{O}_{2}$ during starvation. Accumulation of $\mathrm{H}_{2} \mathrm{O}_{2}$ can oxidize the activity of the ATG4 [40]. Oxidized ATG4 promotes lipidation of LC3/ATG8 for autophagy initiation [41]. The ROS-dependent of LC3-PE accumulates on the autophagosomal membranes, followed by promoting the first steps in autophagosome formation.

ROS can regulate autophagy indirectly through the activation of mitogen activated protein kinase (MAPK) family such as JNK1c-Jun-N-terminal kinase (JNK), p38 and Extracellular Signal-regulated Kinase (ERK) [42]. The MAPK family members are activated in a 3-tier kinase cascade comprising of MAPK kinase kinase (MAPKKK), MAPK kinase (MAPKK) and MAPK [43]. The persistent activation of JNK can trigger a robust increase of cellular ROS production to cause DNA damage. Finally p53 pathway becomes activated by sensing the cellular redox stress. As a transcription factor, p53 transactivates several autophagy inducers which may activate JNK and Sestrin2 which binds to the complex TSC1/ TSC2 to induce phosphorylation and activation of TSC2 finally induce autophagy [44]. Another pathway that plays a role in the ROS-mediated autophagy is the regulation of Akt/ 
Fig. 1. High amount of reactive oxygen species (ROS) production can induce autophagy, apoptosis and necrosis in cells. Oxidative stress induced by ROS can inhibit the mTOR activity, while it can activate AMP-activated protein kinase (AMPK) to stimulate vacuolar protein sorting 34 (Vps34) complex activity which is

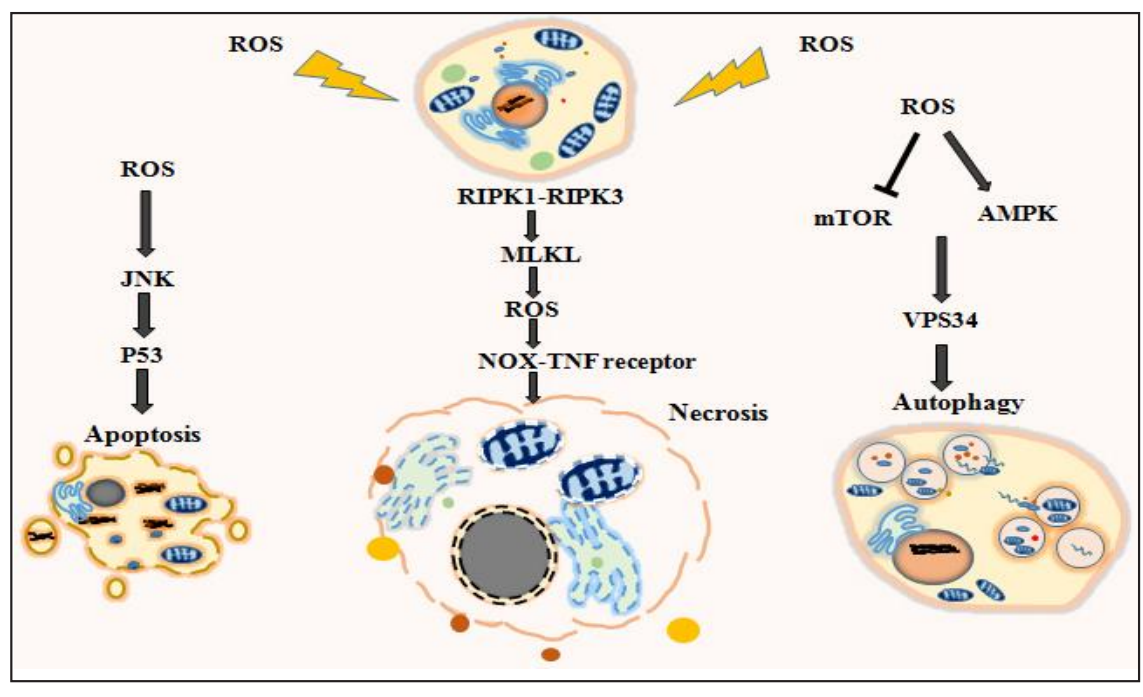
required for initiation of autophagy. ROS can also activate apoptosis though the C-Jun-N-terminal kinase (JNK)/P53 pathway. ROS can injure the mitochondria membrane to release apoptotic factors. Receptorinteracting serine/threonine protein kinase 3 (RIP3) and the kinase activity of RIP1 are essential for stable formation of the RIP1-RIP3 complex, which critically controls downstream ROS production. Moreover, ROS is required for the Receptor-interacting serine/threonine protein kinase 3 (RIP1) mediated necrosis.

mTOR (mechanistic target of rapamycin) and AMPK signaling systems. The Akt/mTOR is a well-known kinase whose activity is modulated by ROS which oxidize the phosphatase and tensin homologue (PTEN) [45]. The activation of autophagy is triggered by inhibiting mTOR [46] and the activation of AMPK by regulating vacuolar protein sorting 34 (VPS34) complex activities [47].

\section{ROS Trigger Apoptosis}

Cell apoptosis initiation originates from extracellular or intracellular signals via the death receptors and the mitochondria-mediated pathways. Upon cell apoptosis initiation, the ROS increases through disrupting intracellular redox homeostasis, and irreversible oxidative modifications of lipid, protein, or DNA, which in turn can activates oxidative stressinduced apoptotic signaling [48]. ROS has been found to trigger the apoptosis of cancer cells via tumor necrosis factor (TNF)-related apoptosis-inducing ligand (TRAIL) [49-51] and upregulate CD95 and TRAIL death receptors by activation of nuclear factor kappa B (NF- $\kappa B$ ) [52]. In addition, ROS-induced activation of JNK can also induce the apoptotic signaling [53, 54]. JNK is a member of the MAPK family. Increasing evidence indicates a crucial role of JNK in mitochondrial dysfunction with subsequent initiation of apoptosis. Shikonin, a natural naphthoquinone derivative, induces apoptosis in various cancer cells, treatment of K562 cells with shikonin resulted in profound induction of apoptosis followed by rapid production of ROS and marked activation of JNK and p38 which lead to the activation of the apoptosis pathway [55]. Activation of ROS/JNK can also elevate and sustain p53 activity leading to robust outcome of apoptosis in cancer cells [56]. The redox-sensitive MAPK kinase and apoptosis signal-regulating kinase 1 (ASK1) are the upstream of ROS/JNK. ASK1 activity is inhibited by interactions with redox proteins (Grx and thioredoxin (Trx1)). ROS mediate Trx1 dissociation from the ASK1-Trx1 complex, and recruit tumor necrosis factor receptorassociated factors to the complex. Activated ASK1 signals down-regulate JNK activation and induces apoptosis either via mitochondrial signaling or via transcription of AP-1-dependent proapoptotic genes [57]. Additionally, ROS-mediated disruption of the mitochondrial ASK1/ ASK2/Trx2 complex induces cytochrome c release [58]. When the ER stress occurs, ROS can 
be elevated to induce the neighboring mitochondria for accentuating the onset of intrinsic apoptosis [59]. Flavone, as the antioxidant can protect myocardial ischemia/reperfusion injury anti-apotosis effect [60].

\section{Necrosis Induced by ROS}

Necrosis is a type of cell death that is different from apoptotic cell death. The programmed necrosis induced by TNF has been termed necroptosis [61]. Receptor-interacting serine/ threonine protein kinase 3 (RIP3) is a protein kinase, which can cause cell death in many cell lines due to its high expression [62-64]. Programmed necrosis is controlled by the action of two serine/threonine kinases, RIP1 and RIP3. The phosphorylation of RIP1 and RIP3 is critical for assembly of the necrosome, an amyloid-like complex that initiates transmission of the pro-necrotic signal [65]. Depletion of RIP3 in cells reduces ROS concentration in necrosisinduced cells and increasing RIP3 levels increase ROS production in contrast. The effects of RIP3 in necrosis induction carried out through increasing energy metabolism-associated ROS production [66]. Study proves the phosphorylation of RIP1 and RIP3 stabilizes their association within the pronecrotic complex, activates the pronecrotic kinase activity, and triggers ROS production [67]. The enhanced production of mitochondrial ROS due to RIP1 phosphorylation-dependent activation can be regulated by the interaction between signal transducer and activator of transcription 3 (STAT3) and the mitochondrial electron transport chain complex I subunit GRIM-19. STAT3 interacts with GRIM-19, which brings about the accumulation of STAT3 and GRIM-19 in the mitochondria, where they induce an increase of ROS production and cell death by necroptosis [68]. Moreover, direct interactions between RIP3 and the enzymes glutamate-ammonia ligase (GLUL), glutamate dehydrogenase 1 (GLUD1) and glycogen phosphorylase (PYGL) increase energy metabolism and mitochondrial ROS production [11]. During necrosis induction, cell surface NADPH oxidase NOX enzyme complexes can interact with the TNF receptor which is also responsible for death-inducing ROS during necrosis [61]. Among the ROS-induced necrosis, mixed lineage kinase domainlike (MLKL) have been identified as a key RIP3 downstream component of TNF-induced necrosis. MLKL is also involved in generation of ROS and the late-phase activation of JNK during TNF-induced necrosis [69-71].

\section{Ferroptosis Induced by ROS}

Ferroptosis is a type of iron-dependent, oxidative cell death which can be triggered by structurally diverse small molecules (e.g. erastin, sulfasalazine and RSL3). Ferroptosis results from antioxidant system dysfunction leading to the loss of cellular redox homeostasis. The ferroptosis is distinct from apoptosis [72, 73]. The classic features of apoptosis, such as mitochondrial cytochrome c release, caspase activation, and chromatin fragmentation, are not observed in RSL induced cell death. However, ferroptosis is featured by association with increased levels of intracellular ROS and inhibition effect by iron chelation or genetic inhibition [74]. The increases of ROS lead to cell detachment and ferroptosis. However, ROS accumulation and ferroptosis were suppressed by treatment with the iron chelator deferoxamine [75]. SLC7A11 is a component of a plasma membrane transporter that mediates $\mathrm{Na}^{+}$independent cellular uptake of extracellular cystine in exchange for intracellular glutamate [76]. The p53-mediated transcriptional repression of SLC7A11 is critical for ROSinduced ferroptosis. The p53 inhibits cystine uptake and sensitizes cells to ferroptosis [77]. Last year, scientists found that the p53-mediated activation of spermine N 1-acetyltransferase 1 (SAT1) contributes significantly to ferroptotic responses. SAT1 is a rate-limiting enzyme in polyamine catabolism critically involved in the conversion of spermidine and spermine back to putrescine. Surprisingly, activation of SAT1 expression induces lipid peroxidation and sensitizes cells to undergo ferroptosis upon ROS-induced stress [78]. 
Fig. 2. Robust production of reactive oxygen species (ROS) can damage mitochondria and DNA. ROS production has been linked to cytochrome P450 enzymes (CYP) activity which is mediated by xenoreceptors aryl hydrocarbon receptor (AhR), pregnant $X$ receptor (PXR), and the constitutive androstane receptor (CAR). Anti-oxidant system consist of (1) enzymatic antioxidants such

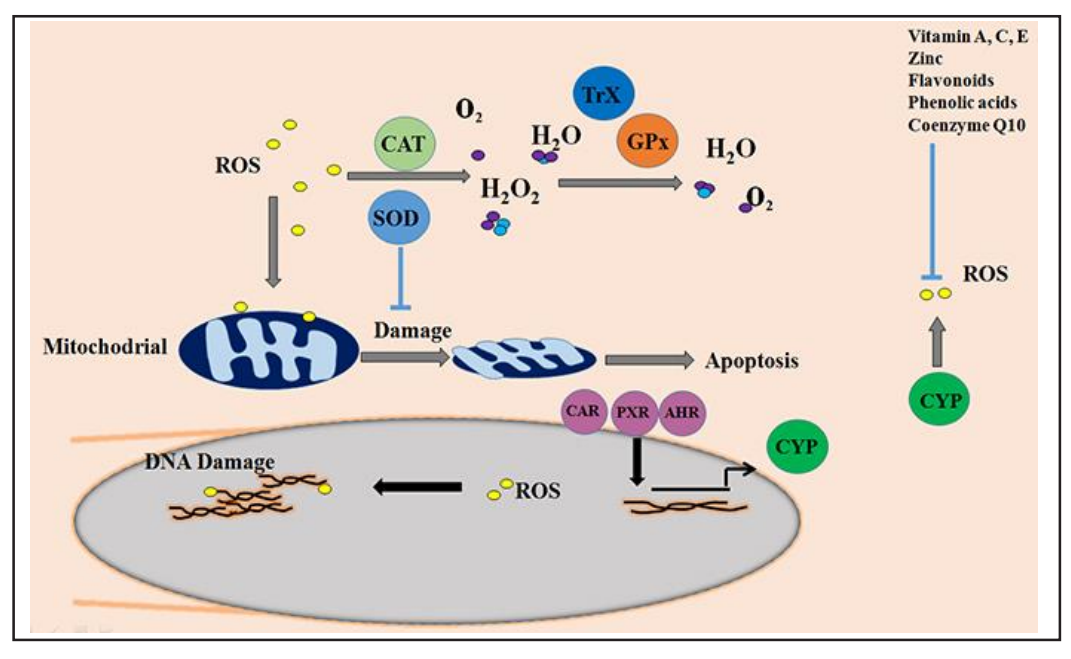
as superoxide dismutase (SOD), catalase (CAT), glutathione peroxidase (GPx) and thioredoxin (Trx) as well as the non-enzymatic antioxidants. The enzymatic antioxidants can directly or indirectly catalyze the ROS to protect the cells. Non-enzymatic antioxidants can neutralize the oxidative effect by promotion of antioxidative enzyme or directly processing oxidative chain reaction.

\section{Endogenous Antioxidant System}

Antioxidants can counteract free radicals and neutralize oxidants. The general endogenous antioxidant system consist of (1) enzymatic antioxidants like SOD, catalase (CAT) and glutathione peroxidase (GPx), and Trx; (2) hydrophilic antioxidants such as urate, ascorbate, glutathione and flavonoids; (3) lipophilic radical antioxidants such as tocopherol, carotenoid and ubiquinol. Antioxidants can be also classified according to their source including endogenous synthesis such as enzymes, and small molecules as well as exogenous diets such as phenolics, flavonoids, phenolic acids, carotenoids, vitamins and minerals [79] (Fig. 2).

\section{Enzymatic Antioxidants}

Enzymatic antioxidants consist of SOD, CAT, GPx and Trx system. The enzymatic antioxidants have more effective protective effects against active and massive oxidative attack due to the ability to decompose ROS [80]. Therefore, this set of antioxidants play important roles in disease conditions including acute hyperoxia injury, radiation injury, lung transplantation and inflammation.

SOD and CAT are the best antioxidants in vivo. SODs found in human can be classified into: cytosolic CuZn-SOD, mitochondrial Mn-SOD and extracellular SOD. The SOD can catalyze superoxide into oxygen and hydrogen peroxide [81]. SOD seems to be the first line of defense against oxygen-derived free radicals and can be rapidly induced in some conditions when exposed to the oxidative stress [82]. CAT can neutralize the hydrogen peroxide through decomposing it into molecular oxygen and water.

It is now well established that the mitochondria are the major producers of ROS and also the main targets of ROS. Massive accumulated ROS and free radicals in mitochondria lead to elevated expression of Mn-SOD to inhibit oxidative damage in mitochondria. The accumulation of ROS can induce mitochondrial permeability transition and disrupt the mitochondrial membrane stability [83]. Disruption of mitochondrial outer membrane will cause the release of cytochrome $\mathrm{c}$ and other pro-apoptotic factors, such as serine protease 


\section{Cellular Physiology Cell Physiol Biochem 2017;44:532-553

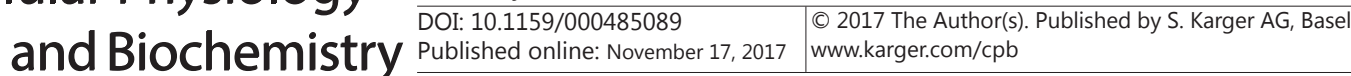 \\ He et al.: Antioxidants and Cellular Homeostasis}

OMI/HtrA2, Smac/Diablo, endonuclease G, and apoptosis inducing factor (AIF), ultimately triggering caspase activation and cell death [84]. A study of kidney transplant patients shows apparent roles of SOD in protecting the allograft from ischemia-reperfusion injury [85].

GPxs belong to a family of phylogenetically related enzymes [86]. The GPx family consists of three evolutionary groups: GPx1/GPx2, GPx3/GPx5/GPx6 and GPx4/GPx7/GPx8 [87]. GPxs can use GSH as a reductant to catalyze $\mathrm{H}_{2} \mathrm{O}_{2}$ or organic hydroperoxides into water or the corresponding alcohols, respectively [88]. Members of GPxs have anti-oxidative function at different cellular components, GPx1 is present ubiquitously in the cytosol and mitochondria, GPx2 in the cytosol and nucleus, and GPx3 in the plasma, GPx4 is membrane-associated and appears to protect membranes from oxidative challenge [89]. Study found that the loss of GPx1 increased production of $\mathrm{H}_{2} \mathrm{O}_{2}$ in mouse embryonic fibroblasts and muscles of GPx1 KO mice [90]. GPxs can regulate the concentration of hydroperoxide mediators therefore affect the several pathways of physiological importance has been shown for GPx1 in insulin signaling and GPx4 in cell survival/proliferation and GPx5 in spermatogenesis [86].

The Trx antioxidant system, composed by NADPH, thioredoxin reductase (TrxR), and Trx, is very important in against oxidative stress as endogenous antioxidant system. Trx antioxidants have function in DNA and protein repairing by reducing ribonucleotide reductase as well as methionine sulfoxide reductases. In addition, Trx systems have been found to be involved in response to the immune response [91]. Homodimeric TrxR is a member of the pyridine nucleotide-disulfide oxidoreductase family which includes TrxR, glutathione reductase (GR), TryR, alkyl hydroperoxide reductase, lipoamide dehydrogenase, and mercuric reductase [92]. Trx and TrxR are the dimeric FAD-containing enzyme that catalyzes the NADPH-dependent reduction of the active-site disulfide in oxidized Trx $\left(\operatorname{Trx}-\mathrm{S}_{2}\right)$ to give a dithiol in reduced $\operatorname{Trx}\left[\operatorname{Trx}-(\mathrm{SH})_{2}\right]$ [93]. Trx- $(\mathrm{SH})_{2}$ is a hydrogen donor for ribonucleotide reductase and a disulfide reductase regulating thiol redox [94]. Trx systems in cells can use the thiol and selenol groups to maintain redox level. Trx and its binding proteins (ASK1 and TBP2) appear to control apoptosis or metabolic states such as carbohydrate and lipid metabolism [95]. Both GSH system and Trx system can defense oxidative stress via the efficient removal of various ROS [96]. Cytosolic Trx1 and mitochondrial Trx2 are the major disulfide reeducates that affect cell proliferation and viability. The reduced/dithiol form of Trxs binds to ASK1 and inhibits its activity to induce apoptosis. When Trx is oxidized, it dissociates from ASK1 and apoptosis is induced [97]. Another important gene which can directly regulate antioxidant proteins expression is factor nuclear erythroid 2-related factor 2 (NRF2), a transcription factor. A small amount of oxidative stress will trigger NRF2 activation to induce of cytoprotective gene expression (cysteine uptake transporter, heme oxygenase 1) that is essential for cytoprotection and cell survival [98]. At a normal condition, NRF2 interacts with Kelch-like ECH-associated protein 1 (KEAP1). Once sensing the elevated ROS signals, ROS can oxidize redox-sensitive cysteine residues on KEAP1 in NRF2-KEAP1 complex, lead to KEAP1 release from NRF2. The free NRF2 will next translocates to the nucleus, and forms the heterodimerizes with the small MAF protein to bind to antioxidantresponsive elements (AREs) within the regulatory regions of multiple antioxidant genes which regulates their expression $[99,100]$.

\section{Non-enzymatic Antioxidants}

Vitamin A or retinol is a carotenoid produced in the liver and resulted from the breakdown of $\beta$-carotene. Vitamin A can directly bind peroxyl radicals before they propagate peroxidation to lipids [101]. CoQ10 can neutralize the oxidative effect of lipid peroxyl radicals and regenerate vitamin E [102]. Vitamin C is effective in scavenging the superoxide radical anion, hydrogen peroxide, hydroxyl radical, singlet oxygen and reactive nitrogen oxide [103]. Vitamin E has 8 isoforms which halts lipid peroxidation by donating its phenolic hydrogen to the peroxyl radicals forming tocopheroxyl radicals which are un-reactive and unable to continue the oxidative chain reaction [104]. Vitamin E can be regenerated through vitamin C 


\section{Cellular Physiology Cell Physiol Biochem 2017;44:532-553 \begin{tabular}{l|l|l} 
and Biochemistry Published online: November 17, 2017 & $\begin{array}{l}\text { (c) } 2017 \text { The Author(s). Published by S. Karger AG, Basel } \\
\text { www.karger.com/cpb }\end{array}$ \\
\hline
\end{tabular}}

to sustain their antioxidant potential.

Minerals are a small proportion of dietary antioxidants. The most important minerals which have the anti-oxidative function are selenium and zinc. Minerals are the components of antioxidant enzymes which are important for activity maintenance of enzymes [105]. Zinc is an inhibitor of NADPH oxidases which catalyze the production of the singlet oxygen radical from oxygen by using NADPH as an electron donor. Zinc is also a component of superoxide dismutase which is an important antioxidant enzyme that converts the singlet oxygen radical into hydrogen peroxide. Zinc induces the production of metallothionein that is a scavenger of the hydroxyl radical. Zinc also acts as an effective anti-inflammatory and antioxidant agent which inhibits TNF- $\alpha$-induced NF- $\kappa B$ activation [106].

Except for the vitamins and minerals, many metabolites such as uric acid, biblirubin, and melatonin exist antioxidative function. Studies report that uric acid can prevent peroxynitrite-induced protein nitrosylation, lipid and protein peroxidation and an inactivation of tetrahydrobiopterin, which results in scavenging free radical and chelating transitional metal ions [107]. The uric acid is also considered as the antioxidant to protect central nervous system (CNS) [108]. However, even though the uric acid can prevent the oxidative stress, as the metabolite of purines, its level is usually higher in obesity and diabetes patients which will be a danger sign for the metabolic disease. Bilirubin, the primary form (unconjugated form) of bilirubin circulating in healthy individuals, has antioxidant properties [109]. Recent studies report bilirubin treatment can increase the nuclear accumulation of NRF2 proteins and activation of NRF2 which will up-regulate heme-oxygenase-1 (HO-1) expression in HepG2 cells and primary mouse hepatocytes [110]. Melatonin is a tryptophan metabolite. Studies demonstrate one melatonin molecule has the capacity to scavenge up to 10 molecules of ROS. Melatonin improves the activities of several respiratory chain complexes, thereby reducing electron leakage and free-radical generation [111]. Except for the melatonin itself, its metabolites (N1-acetyl-N2-formyl-5-methoxykynuramine (AFMK), $\mathrm{N}$-acetyl-5-methoxyknuramine (AMK)) have been found to protect cells from the ROS [112].

Flavonoids consist of flavonols, anthocyanins, isoflavonoids, flavanones and flavones. The antioxidant activity of flavonoids depends on the arrangement of functional groups base on structure. Both the configuration and total number of hydroxyl groups substantially influence the mechanism of the antioxidant activity [113]. The B ring hydroxyl configuration is the most significant determinant of ROS scavenging [114]. Phenolic acids are composed of hydroxycinnamic and hydroxybenzoic acids. They are ubiquitous in plant materials and sometimes present as esters and glycosides. They have antioxidant activity as the chelators and free radical scavengers with special impact over hydroxyl and peroxyl radicals, superoxide anions and peroxynitrites [115]. Carotenoids are a group of natural pigments that are synthesized by plants. The main antioxidant property of carotenoids is that the exciting carotenoids dissipate the newly acquired energy through a series of rotational and vibrational interactions with the solvent, thus returning to the unexcited state and allowing them to quench more radical species. This can occur while the carotenoids have conjugated double bonds. The only free radicals that completely destroy these pigments are peroxyl radicals. Carotenoids are relatively un-reactive but may also decay and form non-radical compounds that may terminate free radical attacks by binding to these radicals [116].

\section{ROS and diseases}

\section{Oxidative Stress and Neurodegenerative Diseases}

Neurodegenerative diseases include Parkinson's disease (PD), Alzheimer's disease (AD), multiple sclerosis and amyotrophic lateral sclerosis. In these diseases, the nerve cells from brain and spinal cord are suffered from mitochondrial dysfunctions as well as excitotoxicity and finally apoptosis, which lead to either functional loss or sensory dysfunctions. Since the brains have a high metabolic rate and relatively reduced capacity for cellular regeneration, nerve cells in brain area are particularly susceptible damaged by ROS shown in Fig. 3. The 
Fig. 3. Oxidative stress caused by reactive oxygen species (ROS) accumulate in different organ will persistently destroy the cells, which may lead to diseases. In brain, ROS will damage the nerve cells which cause neurodegenerative diseases associated with dysfunction of Alzheimer's disease related presenilin-1 and 2 genes (PSEN1 and PSEN2) as well as Parkinson's disease related genes (PARKIN and PINK-1); In gut, ROS will trigger C-Jun-N-terminal kinase (JNK), protein kinase $\mathrm{C}(\mathrm{PKC})$, and

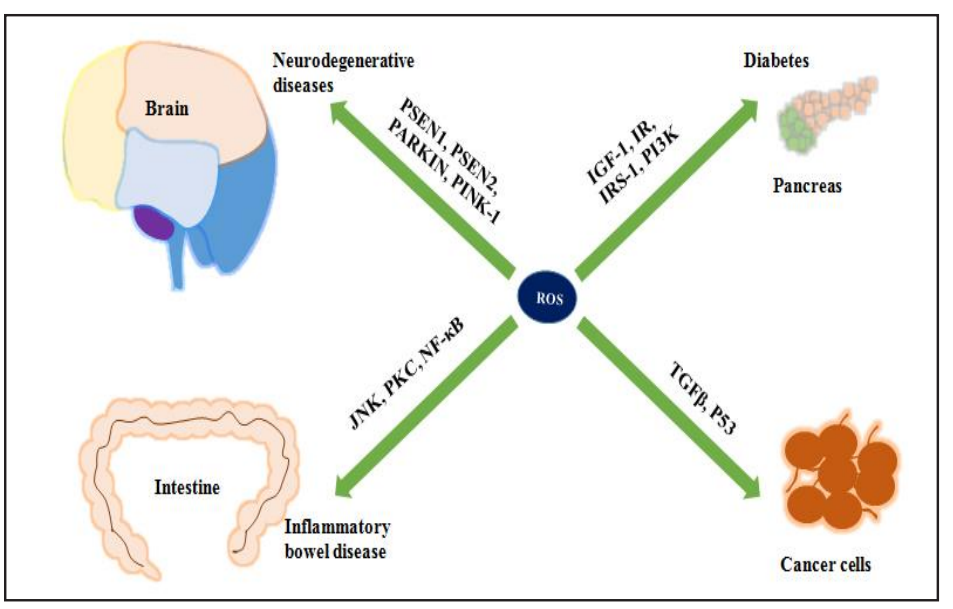
Nuclear factor kappa B (NF- $\kappa \mathrm{B})$ to damage the gut barrier as well as the microbial balance, which lead to the inflammatory bowel disease; ROS will also cause the DNA damage through p53 and dysregulation of transforming growth factor $\beta$ (TGF $\beta$ ) in the normal cell which disrupt cell cycle control and may cause cancer; In pancreas, ROS will inhibit insulin or insulin-like growth factor (IGF)-1, insulin receptor (IR), insulin receptor substrate (IRS)-1 and phosphatidylinositol-3 kinase (PI3K)/Akt kinases and cause the $\beta$-cells damage, which decrease the insulin secretion and may cause the diabetes.

neuronal biochemical composition contain large amount of unsaturated lipids, which are metabolized in peroxidation and oxidative modification. Because brain is not particularly enriched in antioxidant defenses, the brain is highly susceptible to ROS $[117,118]$ and in general the neural cells are more susceptible to oxidative damage as compared to other body tissues. Damage within specific brain region caused by ROS has been reported in the case of $\mathrm{PD}, \mathrm{AD}$ and amyotrophic lateral sclerosis. For example, lipid peroxidation markers have been identified in the cortex and hippocampus of $\mathrm{AD}$ as well as spinal fluid from patients with amyotrophic lateral sclerosis [119]. It has been found that the protein oxidation marker increased in the hippocampus of AD patients [120] and motor neurons of PD patients [121] DJ-1 functions in reducing oxidative stress and transcriptional regulation. Dysfunction of DJ-1 might result in the onset of PD. DJ-1 has general cytoprotective function and antioxidant properties which regulates the extent of stroke-induced damage and neurodegeneration in AD. Indeed, several disease-causing gene mutations in AD related genes (PSEN1, PSEN2) and PD related genes (PARKIN, PINK-1) as well as AD susceptibility gene polymorphism (APOE4) are associated with the increases in oxidative damage and/or vulnerability of oxidative insults [122].

In clinical treatment, many natural and synthetic drugs have been tested. The puerarin is an extract of kudzu roots. Puerarin has been reported to possess neuroprotective function [123]. In dopaminergic neuronal degeneration rat model, puerarin treatment attenuates the disease as reduction of oxidative stress. As predicted, glutathione and catalase, KEAP1 and NEF-2 was elevated. The puerarin activated the NRF2/ARE pathway to clear the ROS may protect the neuron [124].

Gastrodin, is a main component extracted from the rhizome of Gastrodia elata, was found to have neuroprotective effects in PD models, study shows that the heme oxidase 1 , superoxide dismutase, glutathione levels as well as NRF2 nuclear translocation were increased in 1-methyl-4-phenyl-1, 2,3, 6-tetrahydropyridine-intoxicated mice treated with gastrodin [125]. Another study demonstrates gastrodin can improved learning and memory abilities of $\mathrm{Tg} 2576$ transgenic mice and attenuated intracellular ROS level. Study found the expression levels of BACE1 (sporadic AD relevant protein), activated PKR (pPKRThr446) and activated eIF $2 \alpha$ (peIF2 $\alpha$ Ser51) were elevated in the brains of mice and $\mathrm{H}_{2} \mathrm{O}_{2}$-stimulated cells [126].

\section{KARGER}




\section{Cellular Physiology Cell Physiol Biochem 2017;44:532-553

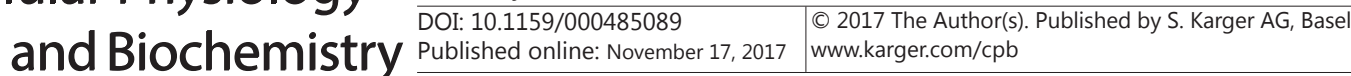 \\ He et al.: Antioxidants and Cellular Homeostasis}

Sulphoraphane is an isothiocyanate and sulphoxythiocarbamate that has anti-oxidative properties as an alternative candidate for AD therapy [127]. Study shows sulforaphane can ameliorated the cognitive function of $A \beta$-induced $A D$ mouse models [128] and decreased locomotor activity in mice with AD-like lesions [129]. Furthermore, sulforaphane protected the brain from $A \beta$-induced oxidative cell death via activation of NRF2 signaling cascade [130] which induces cytoprotective proteins including HO-1 in the CNS [131]. Sulforaphane significantly attenuated the levels of microRNA-146a which is selectively upregulated in the temporal cortex and hippocampus of AD brains. Sulforaphane can also reduce STAT1 activation as well as NLR family, pyrin domain-containing3 (NLRP3) inflammasome activation [132].

\section{Oxidative Stress and IBD}

In general, Inflammatory Bowel Disease (IBD) comprises of the chronic relapsing inflammatory disorders, i.e. Crohn's disease and ulcerative colitis. The precise etiology of IBD is still unknown. However, it is widely accepted that IBD is caused by the combinatory factors including genetics, gut microbiota, the host immune system and environmental factors. These factors interact with an outcome of disruption of intestinal homeostasis resulting in dysregulated inflammatory responses of the gut. Since inflammation is tightly associated with the formation of reactive intermediates, including reactive oxygen and nitrogen species, the oxidative stress become the potential mechanism underlying the pathophysiology of IBD. The host produces ROS as an evolutionarily conserved response to microbes or infections. However, chronic and excessive ROS production activates host inflammatory pathways and results in oxidative stress [133]. During IBD development, oxidative stress contributes to chronic inflammation and dysbiosis, control of oxidative stress may help to maintain the intestinal homeostasis $[134,135]$. ROS can induce inflammation by triggering JNK, protein kinase $\mathrm{C}$, growth factor tyrosine kinase receptor, and extracellular signal-regulated kinase signaling pathways. Several inflammatory transcription factors including NF- $\kappa$ B are redox sensitive and trigger cellular inflammation [136]. In IBD patients, chronic oxidative stress leads to a tissue destruction and disrupts the microbial balance. Studies have found some beneficial microbes function through fermentation and microbial metabolic products help to prevent the gut damage $[137,138]$. However, the human clinical trials showed the variables results about the microbes function in IBD, the causal effect of the microbiotia with the development of IBD is still under active investigation shown in Fig. 3 [138, 139].

Coumarins comprise a large class of cinnamic acid-derived phenolic compounds found particularly in edible plants from different botanical families. Coumarins have antioxidant properties which can be used as antioxidant additives [140]. Study demonstrates that coumarin derivatives promote differential effects on the macroscopic and clinical parameters of the intestinal inflammatory process. Coumarin derivatives (fraxetin, esculin and daphnetin) reduced the incidence of diarrhoea, while the latter two additionally reduced the damage score and colonic weight [141].

Berberine is the principal component of many popular medicinal plants. Study finds the berberine functions as antioxidant through directly scavenging of ROS/RNS and suppression of ROS/RNS production [142]. Cells treated with berberine will induce expression of antioxidant related gene such as antioxidant defense (reduced-glutathione and superoxide dismutase) and oxidant-sensitive proteins (HO-1 and NRF2) [143].

Curcumin belongs to polyphenol, is the major representative of curcuminoids and the main chemical constituents of the spice turmeric as well as curry powder. Curcumin has two phenolic $\mathrm{O}-\mathrm{H}$ groups and one methylene $\mathrm{CH} 2$ group that are capable of $\mathrm{H}$ bond-dissociation enthalpy, while trolox has only one phenolic $\mathrm{O}-\mathrm{H}$. Therefore, the presence of two identical $\mathrm{OH}$ groups as well as methylene $\mathrm{CH} 2$ group in curcumin can easily undergo successive oxidations compared to trolox [144]. Study demonstrates that curcumin shows important antioxidant effects as decrease of ROS/RON production, as well as increase of antioxidant enzymes [145]. 


\section{Cellular Physiology Cell Physiol Biochem 2017;44:532-553

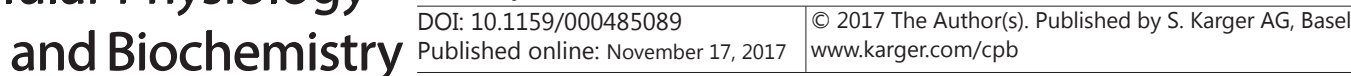 \\ He et al.: Antioxidants and Cellular Homeostasis}

\section{Oxidative Stress and Cancer}

In many types of cancer, an increased oxidative stress has been observed as common feature compared with normal cells. ROS have multiple cellular functions in tumor cells depending on the radical form, concentration and cellular location. ROS induced DNA and protein damage can contribute to cancer initiation through cellular signaling pathways which are associated with tumor cell proliferation, survival and tumor progression shown in Fig. 3. Cancer cells have higher metabolism level than normal cells; they can continuously produce and maintain higher ROS concentrations to maintain their high proliferation rate. The produced ROS can cause oxidative damage of DNA, which in turn to generate mutations in DNA that enhances both the processes of aging and carcinogenesis [146, 147]. IкB kinase $\beta$ (IKK $\beta$ ), an NF- $\kappa B$ activator, links ROS with carcinogenesis. Study demonstrates IKK $\beta$ is involved in chemically induced liver cancer with enhancing ROS production, JNK activation, and hepatocyte death in the IKK $\beta$ liver specific KO mice. Oral administration of an antioxidant successfully blocks JNK activation and compensatory cell proliferation in carcinogenesis mice [148]. In another case, TAK1 is an intracellular hub molecule that regulates NF- $\mathrm{B}$, TAK1 mutations were identified in patients with diffuse, large B-cell lymphoma and prostate cancer in humans [149]. Moreover, ROS can activate the MAPK pathways which the activation of ERK, JNK, and p38 MAPK signaling proteins were involved in apoptosis via ROS generation. Studies have demonstrated the MAPK pathways, plays a pivotal role in cell survival and the enhanced protection of cancer cells from apoptosis during tumorigenesis [150]. Modulation of MAPK by Antioxidant is also involved in the therapy such as heart failure model [151].

Study demonstrated that the high production of ROS was contingent on impaired TGF $\beta$ signaling, which leads to the suppression of the antioxidant enzyme GPx1 [152]. ROS can cause DNA damage, which may excite the p53 in normal cells and consequently activate stress responses as well as DNA repairing. Many studies have found the defect of p53 in cancer cells. Depletion of the p53, ROS-mediated DNA damage would accumulate owing to compromised DNA repair function. It would severely promote the genomic instability and lead to an activation of oncogenes and decrease in antioxidants, thus, increase in ROS levels, leading to more DNA damage and genetic instability. These processes form a vicious cycle which can effectively amplify oxidative stress and promote genomic instability as well as cancer development [153]. Because the increase of ROS in cancer cells may play an important role in the initiation and progression of cancer, such intrinsic oxidative stress has been regarded as an adverse event. However, excessive levels of ROS production can also be toxic to the cancer cells. Cancer cells with increased oxidative stress are likely to be more vulnerable to damage by further ROS insults induced by exogenous agents. Therefore, manipulating ROS levels by redox modulation is a way to selectively inhibit cancer cells proliferation $[154,155]$.

Green tea (Camellia sinensis) is rich in catechins, of which epigallocatechin-3-gallate (EGCG) is the most abundant. Studies in animal models of carcinogenesis have shown that green tea and EGCG can inhibit cancer cell proliferation. Tea polyphenols are strong radical scavengers because of the presence of the dihydroxy and trihydroxy groups. Treatment of mice with EGCG increases gene expression of $\gamma$-glutamyltransferase, glutamate cysteine ligase, and hemeoxygenase-1 in an NRF2-antioxidant response element-dependent manner [156]. Recently, treatment of human prostate cancer LNCaP cells with EGCG activates p53 through acetylation at the Lys373 and Lys382 residues along with consequent increase in GSTP1 (a p53 downstream protein expression in time-dependent manner) [157]. Except for the EGCG, berberine is another anti-cancer drug extracted from traditional Chinese herbal medicines such as berberis amurensis [158]. Studies found berberine can binds to oligonucleotides and stabilizes DNA triplexes or G-quadruplexes, inhibits telomerase and topoisomerase to inhibit many kinds of tumors growth. Berberine has ability to scavenge ROS, inhibit lipid peroxidation and reduce the concentration of metal ions in lipid peroxidation [159]. 


\section{Cellular Physiology Cell Physiol Biochem 2017;44:532-553 and BiOChemistry \begin{tabular}{l|l} 
DOI: $10.1159 / 000485089$ & Published online: November 17, 2017 \\
www.karger.com/cpb
\end{tabular}}

He et al.: Antioxidants and Cellular Homeostasis

\section{Oxidative Stress and Diabetes}

Accumulating evidence has proven that mitochondrial ROS overproduction is causally related to diabetes and diabetic complications. ROS play an important role in the development of insulin resistance in the type II diabetes (T2DM) and decrease in the pancreatic $\beta$ cell functions shown in Fig. $3[160,161]$. Studies showed that high glucose activates various enzyme in mitochondrial, including NADPH oxidase, NO synthases and xanthine oxidase [162-164]. In diabetes, oxidation stress will cause $\beta$-cell's glucotoxicity and lipotoxicity [165], which result in an increased toxicity to $\beta$-cell by primary pathogenic process of diabetes: hyperglycemia and hyperlipidemia. Studies in vitro and in vivo have suggested that both high concentration of glucose and lipids are indeed harmful to the $\beta$-cells [166]. High glucose can lead to the oxidative stress which will affect insulin mRNA expression and insulin synthesis. In contrast, antioxidants reagent can rescue the expression of insulin promoter and insulin mRNA in cultured cells [167]. Under normal condition, cells need a bulk of cell signaling pathway such as insulin or insulin-like growth factor (IGF)-1, insulin receptor (IR), insulin receptor substrate (IRS)-1 and phosphatidylinositol-3 kinase (PI3K)/Akt or ERK kinases to maintain the normal physiological status. When ROS production exceeds the normal physiological levels, those signaling pathway will be adversely affected, which resulting in lower level of insulin secretion even insulin resistance [168]. A large number of evidence suggested that oxidative stress plays an important role in the pathogenesis of diabetes, and the pancreas in general has low ROS detoxification capacity therefore is sensitive to ROSinduced damage. For this reason, the study of natural or synthesized antioxidant may be of great beneficial in diabetes and related conditions treatment.

Curcuminoids (including curcumin, demethoxycurcumin and bisdemethoxycurcumin) are turmeric-extracted polyphenolic pigments that possess numerous health benefits such as its anti-oxidative function. Recently, study indicates that curcuminoids supplementation can significantly decrease serum malondialdehyde (MDA) and increase SOD activities in patients with T2DM [169]. The triglyceride-lowering effects of curcuminoids have been confirmed in several experimental studies. Curcuminoids reduce hepatic fat accumulation and prevent steatosis by downregulating lipogenic factors and activating AMPK in liver [170].

Gallic acid is a major bioactive polyphenol possesses antioxidant, anti-inflammatory effects [171]. Growing evident showed that gallic acid exhibited antihyperglycemic and insulin secretagogue properties in streptozotocin-induced insulin deficient diabetic rats [172]. Gallic acid supplementation can regenerates $\beta$-cells of the islets to restore the normal level of insulin and alleviate the oxidative stress [172]. Gallic acid can also stimulates glucose uptake through translocation and activation of GLUT4 in phosphatidylinositol-3 kinase (PI3K)/p-Akt pathway [173]. Gallic acid attenuates high-fat diet fed-streptozotocininduced insulin resistance via partial agonist of PPAR $\gamma$ in experimental type 2 diabetic rats and enhances glucose uptake through translocation and activation of GLUT4 in PI3K/p-Akt signaling pathway [173].

\section{Conclusion}

Generation of ROS is an evolutionarily conserved process that serving an important role in the cell signaling mechanism as well as the cellular defense mechanism against microbial invasion. The active ROS are continuously produced during normal cellular metabolism. Physiological amount of the ROS is considered to function in signal delivering. However, oxidative stress will occurs when excessive amount of ROS generation induced by environmental factor or disease, which will triggers many physiological and pathophysiological processes such as autophagy, apoptosis, and necrosis. Numerous studies have demonstrated that the oxidative stresses are closely associated with IBD, diabetes and cancer.

The antioxidant systems, including enzymatic antioxidants such as SOD, GPxs, Trx as well as the exogenous antioxidants, can manipulate the ROS level by regulating the genes 
expression and related signaling pathways to keep the redox balance and cellular component integrity. Therefore, the antioxidant therapeutic will offers a promising way to prevent and treat the diseases caused by the excessive exposure to ROS.

\section{Abbreviations}

AFMK (N1-acetyl-N2-formyl-5-methoxykynuramine); AhR (Aryl hydrocarbon receptor); AIF (apoptosis inducing factor); AIP (Aryl hydrocarbon receptor interacting protein); AMK (N-acetyl-5-methoxyknuramine); AMPK (AMP-activated protein kinase); AREs (antioxidant-responsive elements); ARNT (Aryl hydrocarbon receptor nuclear translocator); ASK1 (apoptosis signal-regulating kinase 1); CAR (Constitutive androstane receptor); CNS (central nervous system); CoQ (CoEnzyme Q); CYP (Cytochrome P450 enzymes); EGCG (epigallocatechin-3-gallate); ETC (Electron transporting chain); ER (endoplasmic reticulum); GLUD1 (Glutamate dehydrogenase 1); GLUL (Glutamate-ammonia ligase ); GPxs (Glutathione peroxidases); GR (glutathione reductase); GSH (Glutathione); HO-1(heme-oxygenase-1); HSP90 (Heat-shock protein 90kDa); IBD (Inflammatory bowel disease); IGF (Insulin-like growth factor); IKK $\beta$ (IкB kinase $\beta$ ); IR (Insulin receptor); IRS1 (Insulin receptor substrate-1); JNK (C-Jun-N-terminal kinase); KEAP1 (Kelch-like ECHassociated protein 1); MAPK (Mitogen activated protein kinase); MDA (malondialdehyde); mTOR (Mechanistic target of rapamycin); MLKL (Mixed lineage kinase domain-like ); NF$\kappa B$ (Nuclear factor kappa B); NLRP3 (NLR family, pyrin domain-containing3); NOX (NADPH oxidase); NRF2 (nuclear erythroid 2-related factor 2); PXR (Pregnant X receptor); RIP1 (Receptor-interacting serine/threonine protein kinase 1); PYGL (Glycogen phosphorylase); RIP3 (Receptor-interacting serine/threonine protein kinase 3); PI3K (Phosphatidylinositol-3 kinase ); PTEN (phosphatase and tensin homologue); RNS (Reactive nitrogen species); ROS (Reactive oxygen species); SAT1 (spermine N 1-acetyltransferase 1); STAT3 (Signal transducer and activator of transcription 3); SOD (Superoxide dismutase); T2DM (Type II diabetes ); TrxR (thioredoxin reductase); Trx (Thioredoxin); TNF (Tumor necrosis factor); TRAIL (TNF-related apoptosis-inducing ligand); TCA (Tricarboxylic acid cycle); VPS34 (vacuolar protein sorting 34).

\section{Acknowledgements}

This work was supported by grants from the National Key R\&D Program of China (2017YFD0500501), the National Basic Research Program of China (973 Program, 2013CB117301), the National Natural Science Foundation of China (31722054, 31472101 and 31528018), the 111 Project (B16044), National Department Public Benefit Research Foundation (201403047).

\section{Disclosure Statement}

The authors have no Disclosure Statement to declare.

\section{References}

\footnotetext{
1 Nathan C, Cunningham-Bussel A: Beyond oxidative stress: an immunologist's guide to reactive oxygen species. Nat Rev Immunol 2013;13:349-361.

2 Bhattacharyya A, Chattopadhyay R, Mitra S, Crowe SE: Oxidative stress: an essential factor in the pathogenesis of gastrointestinal mucosal diseases. Physiol Rev 2014;94:329-354.
} 


\section{Cellular Physiology Cell Physiol Biochem 2017;44:532-553 \begin{tabular}{l|l|l|}
\hline DOI: 10.1159/000485089 & $\begin{array}{l}\text { C } 2017 \text { The Author(s). Published by S. Karger AG, Basel } \\
\text { www.karger.com/cpb }\end{array}$ \\
\hline
\end{tabular}}

He et al.: Antioxidants and Cellular Homeostasis

3 Ziech D, Franco R, Pappa A, Panayiotidis MI: Reactive oxygen species (ROS)--induced genetic and epigenetic alterations in human carcinogenesis. Mutat Res 2011;711:167-173.

4 Hur J, Sullivan KA, Schuyler AD, Hong Y, Pande M, States DJ, Jagadish HV, Feldman EL: Literature-based discovery of diabetes- and ROS-related targets. BMC Med Genomics 2010;3:49.

5 Newsholme P, Haber EP, Hirabara SM, Rebelato EL, Procopio J, Morgan D, Oliveira-Emilio HC, Carpinelli AR, Curi R: Diabetes associated cell stress and dysfunction: role of mitochondrial and non-mitochondrial ROS production and activity. J Physiol 2007;583:9-24.

-6 de Vries HE, Witte M, Hondius D, Rozemuller AJ, Drukarch B, Hoozemans J, van Horssen J: Nrf2-induced antioxidant protection: a promising target to counteract ROS-mediated damage in neurodegenerative disease? Free Radic Biol Med 2008;45:1375-1383.

7 Wu Z, Du Y, Xue H, Wu Y, Zhou B: Aluminum induces neurodegeneration and its toxicity arises from increased iron accumulation and reactive oxygen species (ROS) production. Neurobiol Aging 2012;33:199 e191-112.

8 Blagosklonny MV: Aging: ROS or TOR. Cell Cycle 2008;7:3344-3354.

$\rightarrow$ Vigneron A, Vousden KH: p53, ROS and senescence in the control of aging. Aging (Albany NY) 2010;2:471474.

10 Herrera B, Alvarez AM, Sanchez A, Fernandez M, Roncero C, Benito M, Fabregat I: Reactive oxygen species (ROS) mediates the mitochondrial-dependent apoptosis induced by transforming growth factor (beta) in fetal hepatocytes. FASEB J 2001;15:741-751.

11 Zhang DW, Shao J, Lin J, Zhang N, Lu BJ, Lin SC, Dong MQ Han J: RIP3, an energy metabolism regulator that switches TNF-induced cell death from apoptosis to necrosis. Science 2009;325:332-336.

12 Scherz-Shouval R, Elazar Z: Regulation of autophagy by ROS: physiology and pathology. Trends Biochem Sci 2011;36:30-38.

$>13$ Blanco S, Hernandez R, Franchelli G, Ramos-Alvarez MM, Peinado MA: Melatonin influences NO/NOS pathway and reduces oxidative and nitrosative stress in a model of hypoxic-ischemic brain damage. Nitric Oxide 2017;62:32-43.

14 Zhang R, Lin YQ Wang WS, Wang XQ: Excessive nNOS/NO/AMPK signaling activation mediated by the blockage of the CBS/H2S system contributes to oxygenglucose deprivationinduced endoplasmic reticulum stress in PC12 cells. Int J Mol Med 2017;40:549-557.

15 Reiniers MJ, van Golen RF, van Gulik TM, Heger M: Reactive oxygen and nitrogen species in steatotic hepatocytes: a molecular perspective on the pathophysiology of ischemia-reperfusion injury in the fatty liver. Antioxid Redox Signal 2014;21:1119-1142.

-16 Chen ZH, Hurh YJ, Na HK, Kim JH, Chun YJ, Kim DH, Kang KS, Cho MH, Surh YJ: Resveratrol inhibits TCDDinduced expression of CYP1A1 and CYP1B1 and catechol estrogen-mediated oxidative DNA damage in cultured human mammary epithelial cells. Carcinogenesis 2004;25:2005-2013.

17 Wang J, Han M, Zhang G, Qiao S, Li D, Ma X: The Signal Pathway of Antibiotic Alternatives on Intestinal Microbiota and Immune Function. Curr Protein Pept Sci 2016;17:785-796.

18 Heilbronn LK, Ravussin E: Calorie restriction and aging: review of the literature and implications for studies in humans. Am J Clin Nutr 2003;78:361-369.

19 Ming LT, Lu Y: Alcoholic Liver Disease: from CYP2E1 to CYP2A5 Curr Mol Pharmacol 2017;10:172-178.

20 Zangar RC, Davydov DR, Verma S: Mechanisms that regulate production of reactive oxygen species by cytochrome P450 Toxicol Appl Pharmacol 2004;199:316-331.

-21 Barouki R, Morel Y: Repression of cytochrome P450 1A1 gene expression by oxidative stress: mechanisms and biological implications. Biochem Pharmacol 2001;61:511-516.

22 Sinha K, Das J, Pal PB, Sil PC: Oxidative stress: the mitochondria-dependent and mitochondria-independent pathways of apoptosis. Arch Toxicol 2013;87:1157-1180.

-23 Serpe L, Canaparo R, Scordo MG, Spina E: Pharmacogenetics of drug-metabolizing enzymes in Italian populations. Drug Metab Pers Ther 2015;30:107-120.

24 Fan P, Li L, Rezaei A, Eslamfam S, Che D, Ma X: Metabolites of Dietary Protein and Peptides by Intestinal Microbes and their Impacts on Gut. Curr Protein Pept Sci 2015;16:646-654.

25 Bondoc FY, Bao Z, Hu WY, Gonzalez FJ, Wang Y, Yang CS, Hong JY: Acetone catabolism by cytochrome P450 2E1: studies with CYP2E1-null mice. Biochem Pharmacol 1999;58:461-463. 


\section{Cellular Physiology Cell Physiol Biochem 2017;44:532-553 \begin{tabular}{l|l|l}
\hline and BOI: 10.1159/000485089 & $\begin{array}{l}\text { C } 2017 \text { The Author(s). Published by S. Karger AG, Basel } \\
\text { www.karger.com/cpb }\end{array}$ \\
\hline
\end{tabular}}

He et al.: Antioxidants and Cellular Homeostasis

-26 Wang Y, Millonig G, Nair J, Patsenker E, Stickel F, Mueller S, Bartsch H, Seitz HK: Ethanol-induced cytochrome P4502E1 causes carcinogenic etheno-DNA lesions in alcoholic liver disease. Hepatology 2009;50:453-461.

27 Lu Y, Cederbaum AI: CYP2E1 and oxidative liver injury by alcohol. Free Radic Biol Med 2008;44:723-738.

28 Bansal S, Liu CP, Sepuri NB, Anandatheerthavarada HK, Selvaraj V, Hoek J, Milne GL, Guengerich FP, Avadhani NG: Mitochondria-targeted cytochrome P450 2E1 induces oxidative damage and augments alcohol-mediated oxidative stress. J Biol Chem 2010;285:24609-24619.

-29 Abdelmegeed MA, Banerjee A, Yoo SH, Jang S, Gonzalez FJ, Song BJ: Critical role of cytochrome P450 2E1 (CYP2E1) in the development of high fat-induced non-alcoholic steatohepatitis. J Hepatol 2012;57:860866.

-30 Cederbaum AI: Role of CYP2E1 in ethanol-induced oxidant stress, fatty liver and hepatotoxicity. Dig Dis 2010;28:802-811.

-31 Abdelmegeed MA, Yoo SH, Henderson LE, Gonzalez FJ, Woodcroft KJ, Song BJ: PPARalpha expression protects male mice from high fat-induced nonalcoholic fatty liver. J Nutr 2011;141:603-610.

-32 Denison MS, Nagy SR: Activation of the aryl hydrocarbon receptor by structurally diverse exogenous and endogenous chemicals. Annu Rev Pharmacol Toxicol 2003;43:309-334.

33 Ma X, Chen J, Tian Y: Pregnane X receptor as the "sensor and effector" in regulating epigenome. J Cell Physiol 2015;230:752-757.

-34 Chai X, Zeng S, Xie W: Nuclear receptors PXR and CAR: implications for drug metabolism regulation, pharmacogenomics and beyond. Expert Opin Drug Metab Toxicol 2013;9:253-266.

-35 Kobayashi K, Hashimoto M, Honkakoski P, Negishi M: Regulation of gene expression by CAR: an update. Arch Toxicol 2015;89:1045-1055.

-36 Smith RA, Hartley RC, Cocheme HM, Murphy MP: Mitochondrial pharmacology. Trends Pharmacol Sci 2012;33:341-352.

-37 Sandoval-Acuna C, Ferreira J, Speisky H: Polyphenols and mitochondria: an update on their increasingly emerging ROS-scavenging independent actions. Arch Biochem Biophys 2014;559:75-90.

-38 Sabharwal SS, Schumacker PT: Mitochondrial ROS in cancer: initiators, amplifiers or an Achilles' heel? Nat Rev Cancer 2014;14:709-721.

-39 Ma X, Zhang S, He L, Rong Y, Brier LW, Sun Q, Liu R, Fan W, Chen S, Yue Z, Kim J, Guan KL, Li D, Zhong Q: MTORC1-mediated NRBF2 phosphorylation functions as a switch for the class III PtdIns3K and autophagy. Autophagy 2017;13:592-607.

-40 Scherz-Shouval R, Shvets E, Fass E, Shorer H, Gil L, Elazar Z: Reactive oxygen species are essential for autophagy and specifically regulate the activity of Atg4 EMBO J 2007;26:1749-1760.

41 Zhang X, Cheng X, Yu L, Yang J, Calvo R, Patnaik S, Hu X, Gao Q, Yang M, Lawas M, Delling M, Marugan J, Ferrer M, Xu H: MCOLN1 is a ROS sensor in lysosomes that regulates autophagy. Nat Commun 2016;7:12109.

42 Torres M, Forman HJ: Redox signaling and the MAP kinase pathways. Biofactors 2003;17:287-296.

43 Sakon S, Xue X, Takekawa M, Sasazuki T, Okazaki T, Kojima Y, Piao JH, Yagita H, Okumura K, Doi T, Nakano H: NF-kappaB inhibits TNF-induced accumulation of ROS that mediate prolonged MAPK activation and necrotic cell death. EMBO J 2003;22:3898-3909.

44 Bensaad K, Cheung EC, Vousden KH: Modulation of intracellular ROS levels by TIGAR controls autophagy. EMBO J 2009;28:3015-3026.

45 Salmeen A, Barford D: Functions and mechanisms of redox regulation of cysteine-based phosphatases. Antioxid Redox Signal 2005;7:560-577.

46 Hara T, Takamura A, Kishi C, Iemura S, Natsume T, Guan JL, Mizushima N: FIP200, a ULK-interacting protein, is required for autophagosome formation in mammalian cells. J Cell Biol 2008;181:497-510.

-47 Kim J, Kim YC, Fang C, Russell RC, Kim JH, Fan W, Liu R, Zhong Q, Guan KL: Differential regulation of distinct Vps34 complexes by AMPK in nutrient stress and autophagy. Cell 2013;152:290-303.

48 Song P, Zhang R, Wang X, He P, Tan L, Ma X: Dietary grape-seed procyanidins decreased postweaning diarrhea by modulating intestinal permeability and suppressing oxidative stress in rats. J Agric Food Chem 2011;59:6227-6232.

49 Izeradjene K, Douglas L, Tillman DM, Delaney AB, Houghton JA: Reactive oxygen species regulate caspase activation in tumor necrosis factor-related apoptosis-inducing ligand-resistant human colon carcinoma cell lines. Cancer Res 2005;65:7436-7445. 


\section{Cellular Physiology Cell Physiol Biochem 2017;44:532-553 \begin{tabular}{l|l|l|}
\hline and BOI: 10.1159/000485089 & $\begin{array}{l}\text { C } 2017 \text { The Author(s). Published by S. Karger AG, Basel } \\
\text { www.karger.com/cpb }\end{array}$ \\
\hline
\end{tabular}}

He et al.: Antioxidants and Cellular Homeostasis

50 Morioka S, Omori E, Kajino T, Kajino-Sakamoto R, Matsumoto K, Ninomiya-Tsuji J: TAK1 kinase determines TRAIL sensitivity by modulating reactive oxygen species and cIAP. Oncogene 2009;28:2257-2265.

51 Mihaly SR, Ninomiya-Tsuji J, Morioka S: TAK1 control of cell death. Cell Death Differ 2014;21:1667-1676.

52 Ma X, Fan PX, Li LS, Qiao SY, Zhang GL, Li DF: Butyrate promotes the recovering of intestinal wound healing through its positive effect on the tight junctions. J Anim Sci 2012;90:266-268.

53 Kamata H, Honda S, Maeda S, Chang L, Hirata H, Karin M: Reactive oxygen species promote TNFalphainduced death and sustained JNK activation by inhibiting MAP kinase phosphatases. Cell 2005;120:649661.

-54 Chang L, Kamata H, Solinas G, Luo JL, Maeda S, Venuprasad K, Liu YC, Karin M: The E3 ubiquitin ligase itch couples JNK activation to TNFalpha-induced cell death by inducing c-FLIP(L) turnover. Cell 2006;124:601613.

55 Mao X, Yu CR, Li WH, Li WX: Induction of apoptosis by shikonin through a ROS/JNK-mediated process in Bcr/Abl-positive chronic myelogenous leukemia (CML) cells. Cell Res 2008;18:879-888.

56 Shi Y, Nikulenkov F, Zawacka-Pankau J, Li H, Gabdoulline R, Xu J, Eriksson S, Hedstrom E, Issaeva N, Kel A, Arner ES, Selivanova G: ROS-dependent activation of JNK converts p53 into an efficient inhibitor of oncogenes leading to robust apoptosis. Cell Death Differ 2014;21:612-623.

57 Soga M, Matsuzawa A, Ichijo H: Oxidative Stress-Induced Diseases via the ASK1 Signaling Pathway. Int J Cell Biol 2012;2012:439587.

58 Ray PD, Huang BW, Tsuji Y: Reactive oxygen species (ROS) homeostasis and redox regulation in cellular signaling. Cell Signal 2012;24:981-990.

-59 Verfaillie T, Rubio N, Garg AD, Bultynck G, Rizzuto R, Decuypere JP, Piette J, Linehan C, Gupta S, Samali A, Agostinis P: PERK is required at the ER-mitochondrial contact sites to convey apoptosis after ROS-based ER stress. Cell Death Differ 2012;19:1880-1891.

-60 Jian J, Xuan F, Qin F, Huang R: The Antioxidant, Anti-Inflammatory and Anti-Apoptotic Activities of the Bauhinia Championii Flavone are Connected with Protection Against Myocardial Ischemia/Reperfusion Injury. Cell Physiol Biochem 2016;38:1365-1375.

61 Linkermann A, Brasen JH, Darding M, Jin MK, Sanz AB, Heller JO, De Zen F, Weinlich R, Ortiz A, Walczak H, Weinberg JM, Green DR, Kunzendorf U, Krautwald S: Two independent pathways of regulated necrosis mediate ischemia-reperfusion injury. Proc Natl Acad Sci U S A 2013;110:12024-12029.

62 Sun XM, MacFarlane M, Zhuang J, Wolf BB, Green DR, Cohen GM: Distinct caspase cascades are initiated in receptor-mediated and chemical-induced apoptosis. J Biol Chem 1999;274:5053-5060.

63 Oberst A, Dillon CP, Weinlich R, McCormick LL, Fitzgerald P, Pop C, Hakem R, Salvesen GS, Green DR: Catalytic activity of the caspase-8-FLIP(L) complex inhibits RIPK3-dependent necrosis. Nature 2011;471:363-367.

64 Kaiser WJ, Upton JW, Long AB, Livingston-Rosanoff D, Daley-Bauer LP, Hakem R, Caspary T, Mocarski ES: RIP3 mediates the embryonic lethality of caspase-8-deficient mice. Nature 2011;471:368-372.

65 McQuade T, Cho Y, Chan FK: Positive and negative phosphorylation regulates RIP1- and RIP3-induced programmed necrosis. Biochem J 2013;456:409-415.

66 Shulga N, Pastorino JG: GRIM-19-mediated translocation of STAT3 to mitochondria is necessary for TNFinduced necroptosis. J Cell Sci 2012;125:2995-3003.

67 Cho YS, Challa S, Moquin D, Genga R, Ray TD, Guildford M, Chan FK: Phosphorylation-driven assembly of the RIP1-RIP3 complex regulates programmed necrosis and virus-induced inflammation. Cell 2009;137:11121123.

68 Kim YS, Morgan MJ, Choksi S, Liu ZG: TNF-induced activation of the Nox1 NADPH oxidase and its role in the induction of necrotic cell death. Mol Cell 2007;26:675-687.

69 Zhao J, Jitkaew S, Cai Z, Choksi S, Li Q, Luo J, Liu ZG: Mixed lineage kinase domain-like is a key receptor interacting protein 3 downstream component of TNF-induced necrosis. Proc Natl Acad Sci U S A 2012;109:5322-5327.

70 Sun L, Wang H, Wang Z, He S, Chen S, Liao D, Wang L, Yan J, Liu W, Lei X, Wang X: Mixed lineage kinase domain-like protein mediates necrosis signaling downstream of RIP3 kinase. Cell 2012;148:213-227.

71 Wang Z, Jiang H, Chen S, Du F, Wang X: The mitochondrial phosphatase PGAM5 functions at the convergence point of multiple necrotic death pathways. Cell 2012;148:228-243.

-72 Yang WS, Stockwell BR: Synthetic lethal screening identifies compounds activating iron-dependent, nonapoptotic cell death in oncogenic-RAS-harboring cancer cells. Chem Biol 2008;15:234-245. 


\section{Cellular Physiology Cell Physiol Biochem 2017;44:532-553 \begin{tabular}{l|l|l} 
and Biochemistry.1159/000485089 & $\begin{array}{l}\text { (c) 2017 The Author(s). Published by S. Karger AG, Basel } \\
\text { www.karger.com/cpb }\end{array}$ \\
\hline Published online: November 17, 2017
\end{tabular}}

He et al.: Antioxidants and Cellular Homeostasis

73 Yang WS, SriRamaratnam R, Welsch ME, Shimada K, Skouta R, Viswanathan VS, Cheah JH, Clemons PA, Shamji AF, Clish CB, Brown LM, Girotti AW, Cornish VW, Schreiber SL, Stockwell BR: Regulation of ferroptotic cancer cell death by GPX4 Cell 2014;156:317-331.

-74 Yagoda N, von Rechenberg M, Zaganjor E, Bauer AJ, Yang WS, Fridman DJ, Wolpaw AJ, Smukste I, Peltier JM, Boniface JJ, Smith R, Lessnick SL, Sahasrabudhe S, Stockwell BR: RAS-RAF-MEK-dependent oxidative cell death involving voltage-dependent anion channels. Nature 2007;447:864-868.

-75 Dixon SJ, Lemberg KM, Lamprecht MR, Skouta R, Zaitsev EM, Gleason CE, Patel DN, Bauer AJ, Cantley AM, Yang WS, Morrison B, 3rd, Stockwell BR: Ferroptosis: an iron-dependent form of nonapoptotic cell death. Cell 2012;149:1060-1072.

-76 Sato H, Tamba M, Kuriyama-Matsumura K, Okuno S, Bannai S: Molecular cloning and expression of human xCT, the light chain of amino acid transport system xc. Antioxid Redox Signal 2000;2:665-671.

-77 Jiang L, Kon N, Li T, Wang SJ, Su T, Hibshoosh H, Baer R, Gu W: Ferroptosis as a p53-mediated activity during tumour suppression. Nature 2015;520:57-62.

78 Ou Y, Wang SJ, Li D, Chu B, Gu W: Activation of SAT1 engages polyamine metabolism with p53-mediated ferroptotic responses. Proc Natl Acad Sci U S A 2016;113:E6806-E6812.

79 Ratnam DV, Ankola DD, Bhardwaj V, Sahana DK, Kumar MN: Role of antioxidants in prophylaxis and therapy: A pharmaceutical perspective. J Control Release 2006;113:189-207.

-80 Christofidou-Solomidou M, Muzykantov VR: Antioxidant strategies in respiratory medicine. Treat Respir Med 2006;5:47-78.

-81 He L, Eslamfam S, Ma X, Li D: Autophagy and the nutritional signaling pathway. Front Agr Sci Eng 2016;3:222-230

82 Ma X, He P, Sun P, Han P: Lipoic acid: an immunomodulator that attenuates glycinin-induced anaphylactic reactions in a rat model. J Agric Food Chem 2010;58:5086-5092.

83 Zhang M, Shi J, Jiang L: Modulation of mitochondrial membrane integrity and ROS formation by high temperature in Saccharomyces cerevisiae. Electron J Biotechnol 2015;18:202-209.

-84 Suen DF, Norris KL, Youle RJ: Mitochondrial dynamics and apoptosis. Genes Dev 2008;22:1577-1590.

-85 Land W, Schneeberger H, Schleibner S, Illner WD, Abendroth D, Rutili G, Arfors KE, Messmer K: The beneficial effect of human recombinant superoxide dismutase on acute and chronic rejection events in recipients of cadaveric renal transplants. Transplantation 1994;57:211-217.

86 Brigelius-Flohe R, Maiorino M: Glutathione peroxidases. Biochim Biophys Acta 2013;1830:3289-3303.

87 Margis R, Dunand C, Teixeira FK, Margis-Pinheiro M: Glutathione peroxidase family-an evolutionary overview. FEBS J 2008;275:3959-3970.

88 Han P, Ma X, Yin J: The effects of lipoic acid on soybean beta-conglycinin-induced anaphylactic reactions in a rat model. Arch Anim Nutr 2010;64:254-264.

89 Liu H, Zhang J, Zhang S, Yang F, Thacker PA, Zhang G, Qiao S, Ma X: Oral administration of Lactobacillus fermentum 15007 favors intestinal development and alters the intestinal microbiota in formula-fed piglets. J Agric Food Chem 2014;62:860-866.

-90 Loh K, Deng H, Fukushima A, Cai X, Boivin B, Galic S, Bruce C, Shields BJ, Skiba B, Ooms LM, Stepto N, Wu B, Mitchell CA, Tonks NK, Watt MJ, Febbraio MA, Crack PJ, Andrikopoulos S, Tiganis T: Reactive oxygen species enhance insulin sensitivity. Cell Metab 2009;10:260-272.

-91 Lu J, Holmgren A: The thioredoxin antioxidant system. Free Radic Biol Med 2014;66:75-87.

$\$ 2$ Argyrou A, Blanchard JS: Flavoprotein disulfide reductases: advances in chemistry and function. Prog Nucleic Acid Res Mol Biol 2004;78:89-142.

$\$ 93$ Holmgren A: Thioredoxin and glutaredoxin systems. J Biol Chem 1989;264:13963-13966.

\$94 Arner ES, Zhong L, Holmgren A: Preparation and assay of mammalian thioredoxin and thioredoxin reductase. Methods Enzymol 1999;300:226-239.

95 Lillig CH, Holmgren A: Thioredoxin and related molecules--from biology to health and disease. Antioxid Redox Signal 2007;9:25-47.

-96 Papp LV, Lu J, Holmgren A, Khanna KK: From Selenium to Selenoproteins: Synthesis, Identity, and Their Role in Human Health. Antioxid Redox Signal 2007;9:775-806.

-97 Lu J, Holmgren A: Thioredoxin system in cell death progression. Antioxid Redox Signal 2012;17:1738-1747.

-98 Niture SK, Khatri R, Jaiswal AK: Regulation of Nrf2-an update. Free Radic Biol Med 2014;66:36-44.

99 Schieber M, Chandel NS: ROS Function in Redox Signaling and Oxidative Stress. Curr Biol 2014;24:R453-R462. 


\section{Cellular Physiology Cell Physiol Biochem 2017;44:532-553 \begin{tabular}{l|l|l} 
and Biochemistry $\begin{array}{l}\text { DOI.1159/000485089 } \\
\text { Published online: November 17, } 2017\end{array}$ & $\begin{array}{l}\text { C } 2017 \text { The Author(s). Published by S. Karger AG, Basel } \\
\text { www.karger.com/cpb }\end{array}$ \\
\hline
\end{tabular}}

He et al.: Antioxidants and Cellular Homeostasis

100 Shi L, Wu LL, Chen ZG, Yang JR, Chen XF, Yu FY, Zheng F, Lin XY: MiR-141 Activates Nrf2-Dependent Antioxidant Pathway via Down-Regulating the Expression of Keap1 Conferring the Resistance of Hepatocellular Carcinoma Cells to 5-Fluorouracil. Cell Physiol Biochem 2015;35:2333-2348.

101 Jee JP, Lim SJ, Park JS, Kim CK: Stabilization of all-trans retinol by loading lipophilic antioxidants in solid lipid nanoparticles. Eur J Pharm Biopharm 2006;63:134-139.

102 Fan P, Tan Y, Jin K, Lin C, Xia S, Han B, Zhang F, Wu L, Ma X: Supplemental lipoic acid relieves post-weaning diarrhoea by decreasing intestinal permeability in rats. J Anim Physiol Anim Nutr (Berl) 2017;101:136146.

103 Barros AIRNA, Nunes FM, Goncalves B, Bennett RN, Silva AP: Effect of cooking on total vitamin C contents and antioxidant activity of sweet chestnuts (Castanea sativa Mill.). Food Chem 2011;128:165-172.

104 Burton GW, Traber MG: Vitamin-E - Antioxidant Activity, Biokinetics, and Bioavailability. Annu Rev Nutr 1990;10:357-382.

105 Tabassum A, Bristow RG, Venkateswaran V: Ingestion of selenium and other antioxidants during prostate cancer radiotherapy: A good thing? Cancer Treat Rev 2010;36:230-234.

106 Prasad AS, Bao B, Beck FWJ, Kucuk 0, Sarkar FH: Antioxidant effect of zinc in humans. Free Radic Biol Med 2004;37:1182-1190.

107 Waring WS, Webb DJ, Maxwell SRJ: Systemic uric acid administration increases serum antioxidant capacity in healthy volunteers. J Cardiovasc Pharmacol 2001;38:365-371.

108 Bowman GL, Shannon J, Frei B, Kaye JA, Quinn JF: Uric Acid as a CNS Antioxidant. J Alzheimers Dis 2010;19:1331-1336.

109 Rizzo AM, Berselli P, Zava S, Montorfano G, Negroni M, Corsetto P, Berra B: Endogenous Antioxidants and Radical Scavengers. Bio-Farms for Nutraceuticals: Functional Food and Safety Control by Biosensors. Adv Exp Med Biol 2010;698:52-67.

110 Kim SD, Antenos M, Squires EJ, Kirby GM: Cytochrome P450 2A5 and bilirubin: Mechanisms of gene regulation and cytoprotection. Toxicology Appl Pharm 2013;270:129-138.

111 Martin M, Macias M, Escames G, Reiter RJ, Agapito MT, Ortiz GG, Acuna-Castroviejo D: Melatonin-induced increased activity of the respiratory chain complexes I and IV can prevent mitochondrial damage induced by ruthenium red in vivo. J Pineal Res 2000;28:242-248.

112 Galano A, Tan DX, Reiter RJ: On the free radical scavenging activities of melatonin's metabolites, AFMK and AMK. J Pineal Res 2013;54:245-257.

113 Heim KE, Tagliaferro AR, Bobilya DJ: Flavonoid antioxidants: chemistry, metabolism and structure-activity relationships. J Nutr Biochem 2002;13:572-584.

114 RiceEvans CA, Miller NJ, Paganga G: Structure-antioxidant activity relationships of flavonoids and phenolic acids. Free Radical Bio Med 1996;20:933-956.

115 Terpinc P, Polak T, Segatin N, Hanzlowsky A, Ulrih NP, Abramovic H: Antioxidant properties of 4-vinyl derivatives of hydroxycinnamic acids. Food Chem 2011;128:62-69.

116 Paiva SA, Russell RM: Beta-carotene and other carotenoids as antioxidants. J Am Coll Nutr 1999;18:426433.

-117 Rice AC, Zsoldos R, Chen T, Wilson MS, Alessandri B, Hamm RJ, Bullock MR: Lactate administration attenuates cognitive deficits following traumatic brain injury. Brain Res 2002;928:156-159.

118 Hayashi T, Saito A, Okuno S, Ferrand-Drake M, Dodd RL, Chan PH: Oxidative injury to the endoplasmic reticulum in mouse brains after transient focal ischemia. Neurobiol Dis 2004;15:229-239.

119 Butterfield DA, Castegna A, Lauderback CM, Drake J: Evidence that amyloid beta-peptide-induced lipid peroxidation and its sequelae in Alzheimer's disease brain contribute to neuronal death. Neurobiol Aging 2002;23:655-664.

120 Miller TM, Pestronk A, David W, Rothstein J, Simpson E, Appel SH, Andres PL, Mahoney K, Allred P, Alexander K, Ostrow LW, Schoenfeld D, Macklin EA, Norris DA, Manousakis G, Crisp M, Smith R, Bennett CF, Bishop KM, Cudkowicz ME: An antisense oligonucleotide against SOD1 delivered intrathecally for patients with SOD1 familial amyotrophic lateral sclerosis: a phase 1, randomised, first-in-man study. Lancet Neurol 2013;12:435-442.

121 Aoyama K, Matsubara K, Fujikawa Y, Nagahiro Y, Shimizu K, Umegae N, Hayase N, Shiono H, Kobayashi $\mathrm{S}$ : Nitration of manganese superoxide dismutase in cerebrospinal fluids is a marker for peroxynitritemediated oxidative stress in neurodegenerative diseases. Ann Neurol 2000;47:524-527. 


\section{Cellular Physiology Cell Physiol Biochem 2017;44:532-553 \begin{tabular}{l|l|l} 
and Biochemistry 10.1159/000485089 & $\begin{array}{l}\text { (c) 2017 The Author(s). Published by S. Karger AG, Basel } \\
\text { www.karger.com/cpb }\end{array}$ \\
\hline Published online: November 17, 2017
\end{tabular}}

He et al.: Antioxidants and Cellular Homeostasis

122 Nunomura A, Zhu X, Perry G: Modulation of Parkinson's Disease Associated Protein Rescues Alzheimer's Disease Degeneration. J Alzheimers Dis 2017;55:73-75.

123 Li R, Zheng N, Liang T, He Q Xu L: Puerarin attenuates neuronal degeneration and blocks oxidative stress to elicit a neuroprotective effect on substantia nigra injury in 6-OHDA-lesioned rats. Brain Res 2013;1517:2835.

124 Zhu X, Wang K, Zhang K, Lin X, Zhu L, Zhou F: Puerarin Protects Human Neuroblastoma SH-SY5Y Cells against Glutamate-Induced Oxidative Stress and Mitochondrial Dysfunction. J Biochem Mol Toxicol 2016;30:22-28.

125 Wang XL, Xing GH, Hong B, Li XM, Zou Y, Zhang XJ, Dong MX: Gastrodin prevents motor deficits and oxidative stress in the MPTP mouse model of Parkinson's disease: involvement of ERK1/2-Nrf2 signaling pathway. Life Sci 2014;114:77-85.

126 Zhang JS, Zhou SF, Wang Q, Guo JN, Liang HM, Deng JB, He WY: Gastrodin suppresses BACE1 expression under oxidative stress condition via inhibition of the PKR/eIF2alpha pathway in Alzheimer's disease. Neuroscience 2016;325:1-9.

127 Tarozzi A, Angeloni C, Malaguti M, Morroni F, Hrelia S, Hrelia P: Sulforaphane as a potential protective phytochemical against neurodegenerative diseases. Oxid Med Cell Longev 2013;2013:415078.

128 Kim HV, Kim HY, Ehrlich HY, Choi SY, Kim DJ, Kim Y: Amelioration of Alzheimer's disease by neuroprotective effect of sulforaphane in animal model. Amyloid 2013;20:7-12.

129 Zhang R, Miao QW, Zhu CX, Zhao Y, Liu L, Yang J, An L: Sulforaphane ameliorates neurobehavioral deficits and protects the brain from amyloid beta deposits and peroxidation in mice with Alzheimer-like lesions. Am J Alzheimers Dis Other Demen 2015;30:183-191.

130 Lee C, Park GH, Lee SR, Jang JH: Attenuation of $\beta$-amyloid-induced oxidative cell death by sulforaphane via activation of NF-E2-related factor 2 Oxid Med Cell Longev 2013;2013:313510.

131 Singh K, Connors SL, Macklin EA, Smith KD, Fahey JW, Talalay P, Zimmerman AW: Sulforaphane treatment of autism spectrum disorder (ASD). Proc Natl Acad Sci U S A 2014;111:15550-15555.

132 An YW, Jhang KA, Woo SY, Kang JL, Chong YH: Sulforaphane exerts its anti-inflammatory effect against amyloid-beta peptide via STAT-1 dephosphorylation and activation of Nrf2/HO-1 cascade in human THP-1 macrophages. Neurobiol Aging 2016;38:1-10.

133 Giasson BI, Duda JE, Murray IV, Chen Q, Souza JM, Hurtig HI, Ischiropoulos H, Trojanowski JQ, Lee VM: Oxidative damage linked to neurodegeneration by selective alpha-synuclein nitration in synucleinopathy lesions. Science 2000;290:985-989.

134 Mutlu E, Keshavarzian A, Engen P, Forsyth CB, Sikaroodi M, Gillevet P: Intestinal dysbiosis: a possible mechanism of alcohol-induced endotoxemia and alcoholic steatohepatitis in rats. Alcohol Clin Exp Res 2009;33:1836-1846.

135 Chong WC, Shastri MD, Eri R: Endoplasmic Reticulum Stress and Oxidative Stress: A Vicious Nexus Implicated in Bowel Disease Pathophysiology. Int J Mol Sci 2017;18.

136 Ballal SA, Veiga P, Fenn K, Michaud M, Kim JH, Gallini CA, Glickman JN, Quere G, Garault P, Beal C, Derrien M, Courtin P, Kulakauskas S, Chapot-Chartier MP, van Hylckama Vlieg J, Garrett WS: Host lysozyme-mediated lysis of Lactococcus lactis facilitates delivery of colitis-attenuating superoxide dismutase to inflamed colons. Proc Natl Acad Sci U S A 2015;112:7803-7808.

137 Veiga P, Gallini CA, Beal C, Michaud M, Delaney ML, DuBois A, Khlebnikov A, van Hylckama Vlieg JE, Punit S, Glickman JN, Onderdonk A, Glimcher LH, Garrett WS: Bifidobacterium animalis subsp. lactis fermented milk product reduces inflammation by altering a niche for colitogenic microbes. Proc Natl Acad Sci U S A 2010;107:18132-18137.

138 Bourreille A, Cadiot G, Le Dreau G, Laharie D, Beaugerie L, Dupas JL, Marteau P, Rampal P, Moyse D, Saleh A, Le Guern ME, Galmiche JP, Group FS: Saccharomyces boulardii does not prevent relapse of Crohn's disease. Clin Gastroenterol Hepatol 2013;11:982-987.

139 Bibiloni R, Fedorak RN, Tannock GW, Madsen KL, Gionchetti P, Campieri M, De Simone C, Sartor RB: VSL\#3 probiotic-mixture induces remission in patients with active ulcerative colitis. Am J Gastroenterol 2005;100:1539-1546.

140 Romier B, Schneider YJ, Larondelle Y, During A: Dietary polyphenols can modulate the intestinal inflammatory response. Nutr Rev 2009;67:363-378. 


\section{Cellular Physiology Cell Physiol Biochem 2017;44:532-553 \begin{tabular}{l|l|l} 
and Biochemistry & $\begin{array}{l}\text { DOI: 10.1159/000485089 } \\
\text { Published online: November 17, } 2017\end{array}$ & $\begin{array}{l}\text { C } 2017 \text { The Author(s). Published by S. Karger AG, Basel } \\
\text { www.karger.com/cpb }\end{array}$ \\
\hline
\end{tabular}}

He et al.: Antioxidants and Cellular Homeostasis

141 Witaicenis A, Seito LN, da Silveira Chagas A, de Almeida LD, Jr., Luchini AC, Rodrigues-Orsi P, Cestari SH, Di Stasi LC: Antioxidant and intestinal anti-inflammatory effects of plant-derived coumarin derivatives. Phytomedicine 2014;21:240-246.

142 Shan WJ, Huang L, Zhou Q Meng FC, Li XS: Synthesis, biological evaluation of 9-N-substituted berberine derivatives as multi-functional agents of antioxidant, inhibitors of acetylcholinesterase, butyrylcholinesterase and amyloid-beta aggregation. Eur J Med Chem 2011;46:5885-5893.

143 Zhang X, Liang D, Lian X, Jiang Y, He H, Liang W, Zhao Y, Chi ZH: Berberine activates Nrf2 nuclear translocation and inhibits apoptosis induced by high glucose in renal tubular epithelial cells through a phosphatidylinositol 3-kinase/Akt-dependent mechanism. Apoptosis 2016;21:721-736.

144 Barzegar A, Moosavi-Movahedi AA: Intracellular ROS protection efficiency and free radical-scavenging activity of curcumin. PLoS One 2011;6:e26012.

145 Hanai H, Sugimoto K: Curcumin has bright prospects for the treatment of inflammatory bowel disease. Curr Pharm Des 2009;15:2087-2094.

146 Matsui A, Ikeda T, Enomoto K, Hosoda K, Nakashima H, Omae K, Watanabe M, Hibi T, Kitajima M: Increased formation of oxidative DNA damage, 8-hydroxy-2'-deoxyguanosine, in human breast cancer tissue and its relationship to GSTP1 and COMT genotypes. Cancer Lett 2000;151:87-95.

147 Chan PH: Reactive oxygen radicals in signaling and damage in the ischemic brain. J Cereb Blood Flow Metab 2001;21:2-14.

148 Maeda S, Kamata H, Luo JL, Leffert H, Karin M: IKKbeta couples hepatocyte death to cytokine-driven compensatory proliferation that promotes chemical hepatocarcinogenesis. Cell 2005;121:977-990.

149 Roh YS, Song J, Seki E: TAK1 regulates hepatic cell survival and carcinogenesis. J Gastroenterol 2014;49:185-194.

150 Chan JS, Tan MJ, Sng MK, Teo Z, Phua T, Choo CC, Li L, Zhu P, Tan NS: Cancer-associated fibroblasts enact field cancerization by promoting extratumoral oxidative stress. Cell Death Dis 2017;8:e2562.

151 Martinez PF, Bonomo C, Guizoni DM, Junior SA, Damatto RL, Cezar MD, Lima AR, Pagan LU, Seiva FR, Bueno RT, Fernandes DC, Laurindo FR, Zornoff LA, Okoshi K, Okoshi MP: Modulation of MAPK and NF-954;B Signaling Pathways by Antioxidant Therapy in Skeletal Muscle of Heart Failure Rats. Cell Physiol Biochem 2016;39:371-384.

152 Liu B, Chen Y, St Clair DK: ROS and p53: a versatile partnership. Free Radic Biol Med 2008;44:1529-1535.

153 Trachootham D, Alexandre J, Huang P: Targeting cancer cells by ROS-mediated mechanisms: a radical therapeutic approach? Nat Rev Drug Discov 2009;8:579-591.

154 Hao W, Yuan X, Yu L, Gao C, Sun X, Wang D, Zheng Q: Licochalcone A-induced human gastric cancer BGC823 cells apoptosis by regulating ROS-mediated MAPKs and PI3K/AKT signaling pathways. Sci Rep 2015;5:10336.

155 Young B, Purcell C, Kuang YQ, Charette N, Dupre DJ: Superoxide Dismutase 1 Regulation of CXCR4Mediated Signaling in Prostate Cancer Cells is Dependent on Cellular Oxidative State. Cell Physiol Biochem 2015;37:2071-2084.

156 Shen G, Xu C, Hu R, Jain MR, Nair S, Lin W, Yang CS, Chan JY, Kong AN: Comparison of (-)-epigallocatechin-3gallate elicited liver and small intestine gene expression profiles between C57BL/6J mice and C57BL/6J/ Nrf2 (-/-) mice. Pharm Res 2005;22:1805.

157 Thakur VS, Deb G, Jackson MW, Gupta S: Abstract 5257: Upregulation of glutathione S-transferase P1 by green tea polyphenols: A novel transcriptional target of p53 tumor suppressor gene. Cancer Res 2016;76:5257-5257.

158 Xie J, Ma T, Gu Y, Zhang X, Qiu X, Zhang L, Xu R, Yu Y: Berbamine derivatives: a novel class of compounds for anti-leukemia activity. Eur J Med Chem 2009;44:3293-3298.

159 Saeidnia S, Abdollahi M: Antioxidants: friends or foe in prevention or treatment of cancer: the debate of the century. Toxicol Appl Pharmacol 2013;271:49-63.

160 Chattopadhyay M, Khemka VK, Chatterjee G, Ganguly A, Mukhopadhyay S, Chakrabarti S: Enhanced ROS production and oxidative damage in subcutaneous white adipose tissue mitochondria in obese and type 2 diabetes subjects. Mol Cell Biochem 2015;399:95-103.

161 Kanikarla-Marie P, Jain SK: Role of Hyperketonemia in Inducing Oxidative Stress and Cellular Damage in Cultured Hepatocytes and Type 1 Diabetic Rat Liver. Cell Physiol Biochem 2015;37:2160-2170. 


\section{Cellular Physiology Cell Physiol Biochem 2017;44:532-553

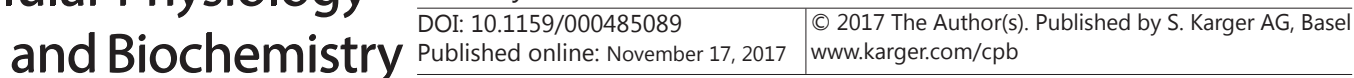 \\ He et al.: Antioxidants and Cellular Homeostasis}

162 Du XL, Edelstein D, Rossetti L, Fantus IG, Goldberg H, Ziyadeh F, Wu J, Brownlee M: Hyperglycemia-induced mitochondrial superoxide overproduction activates the hexosamine pathway and induces plasminogen activator inhibitor-1 expression by increasing Sp1 glycosylation. Proc Natl Acad Sci U S A 2000;97:1222212226.

163 Gupta S, Chough E, Daley J, Oates P, Tornheim K, Ruderman NB, Keaney JF, Jr.: Hyperglycemia increases endothelial superoxide that impairs smooth muscle cell Na+-K+-ATPase activity. Am J Physiol Cell Physiol 2002;282:C560-566.

164 Nishikawa T, Edelstein D, Du XL, Yamagishi S, Matsumura T, Kaneda Y, Yorek MA, Beebe D, Oates PJ, Hammes HP, Giardino I, Brownlee M: Normalizing mitochondrial superoxide production blocks three pathways of hyperglycaemic damage. Nature 2000;404:787-790.

165 Poitout V, Robertson RP: Glucolipotoxicity: fuel excess and beta-cell dysfunction. Endocr Rev 2008;29:351366.

166 Harmon JS, Gleason CE, Tanaka Y, Poitout V, Robertson RP: Antecedent hyperglycemia, not hyperlipidemia, is associated with increased islet triacylglycerol content and decreased insulin gene mRNA level in Zucker diabetic fatty rats. Diabetes 2001;50:2481-2486.

167 Tanaka Y, Gleason CE, Tran PO, Harmon JS, Robertson RP: Prevention of glucose toxicity in HIT-T15 cells and Zucker diabetic fatty rats by antioxidants. Proc Natl Acad Sci U S A 1999;96:10857-10862.

168 Powell DJ, Hajduch E, Kular G, Hundal HS: Ceramide disables 3-phosphoinositide binding to the pleckstrin homology domain of protein kinase B (PKB)/Akt by a PKCzeta-dependent mechanism. Mol Cell Biol 2003;23:7794-7808.

169 Panahi Y, Khalili N, Sahebi E, Namazi S, Karimian MS, Majeed M, Sahebkar A: Antioxidant effects of curcuminoids in patients with type 2 diabetes mellitus: a randomized controlled trial. Inflammopharmacology 2017;25:25-31.

170 Sahebkar A: Curcuminoids for the management of hypertriglyceridaemia. Nat Rev Cardiol 2014;11:123.

171 Mansouri MT, Soltani M, Naghizadeh B, Farbood Y, Mashak A, Sarkaki A: A possible mechanism for the anxiolytic-like effect of gallic acid in the rat elevated plus maze. Pharmacol Biochem Behav 2014;117:4046.

172 Latha RC, Daisy P: Insulin-secretagogue, antihyperlipidemic and other protective effects of gallic acid isolated from Terminalia bellerica Roxb. in streptozotocin-induced diabetic rats. Chem Biol Interact 2011;189:112-118.

173 Gandhi GR, Jothi G, Antony PJ, Balakrishna K, Paulraj MG, Ignacimuthu S, Stalin A, Al-Dhabi NA: Gallic acid attenuates high-fat diet fed-streptozotocin-induced insulin resistance via partial agonism of PPARgamma in experimental type 2 diabetic rats and enhances glucose uptake through translocation and activation of GLUT4 in PI3K/p-Akt signaling pathway. Eur J Pharmacol 2014;745:201-216. 